\title{
Gender Discrimination (GD): A Conceptual Trauma-Based Framework for GD and the Development of Gender Discrimination Inventory
}

\author{
Ibrahim A. Kira1,2, Shuwiekh Hanaa3, Mireille Bujold-Bugeaud1 \\ ${ }^{1}$ Center for Cumulative Trauma Studies, Stone Mountain, GA, USA \\ ${ }^{2}$ Center for the Study of Stress Trauma and Resiliency, Georgia State University, Atlanta, USA \\ ${ }^{3}$ South Valley University, Qina, Egypt \\ Email: kiraaref@aol.com
}

Received 16 October 2015; accepted 25 December 2015; published 28 December 2015

Copyright (C) 2015 by authors and Scientific Research Publishing Inc.

This work is licensed under the Creative Commons Attribution International License (CC BY). http://creativecommons.org/licenses/by/4.0/

(c) (i) Open Access

\begin{abstract}
A comprehensive plausible conceptual model of Gender Discrimination (GD) and accurate measures of its components are lacking. Current study developed a conceptual model of GD derived from the development-based trauma framework (DBT) and constructed measures for GD and its coping dynamics and tested them in two studies on Egyptian female college students. The first study conducted on a sample of 150, and the second study conducted on 311 participants. Exploratory factor analysis in the first sample, and confirmatory factor analysis in the second sample confirmed three components of GD (GD by parents attitudes, GD by parents behavior, and GD by society), and three components of GD coping dynamics (gender identity conflict (GIC), internalized GD, and GD resistance). GD measures are found to have generally good reliability and stability, good construct, and predictive validity. Using path analysis in the second study, GD, controlling for other life traumas, predicted a significant decrease in self-esteem and self-efficacy and increase in existential anxiety, which mediated its effects on PTSD and complex PTSD. GIC and internalized GD further moderated GD effects. GD inventory that includes 6 measures with 33 items can be a parsimonious tool for future research on GD.
\end{abstract}

\section{Keywords}

Development-Based Trauma Framework (DBTF), Gender Discrimination by Parents, Existential Annihilation Anxiety, Gender Identity Conflict, Internalized Gender Discrimination, Gender Discrimination Resistance 


\section{Introduction}

According to the traumatology perspective, different discriminations are various forms of social identity traumas that can have negative effects on mental and physical health. The concept of identity traumas has been proposed in earlier work as part of development-based trauma framework (DBTF) (e.g., Kira, 2001; Kira et al., 2008; Kira, Lewandowski et al., 2014; Kira, Omidy, Fawzi et al., 2015). This framework termed such discriminations as "type III" trauma that is ongoing traumas which start with person's emerging identities early in life without a foreseeable end, and that has a potential of proliferation to other traumas and of developing cumulative and continued effects. Discriminations due to color, race, gender, religion, or other specific attributes, are potentially the most serious kind, in terms of its negative effects, and its persistence. Type III trauma may be internalized by some affected individuals. Internalization of the comparatively degraded status, demeaning public perceptions, and accepting discrimination as legitimate may have negative effects on identity and on self-concept. Endorsed rationalization and submission to inferior status create a sense of violated/hyphenated/or marginalized self, degraded self-worth, and deficient self-efficacy and poor self-control which are keys to mental health (e.g., Corrigan, Watson, \& Barr, 2006). Several studies and meta-analyses substantiate the association of different discriminations with negative health and mental health including post-trauma spectrum disorders such as depression, PTSD, and complex PTSD (e.g., Helms, Nicolas, \& Green, 2010; Kira, Alawneh, Aboumediene, Lewandowski, \& Laddis, 2014; Kira, Ashby, et al., 2013; Kira, Lewandowski, Chiodo, \& Ibrahim, 2014; Kira, Smith, Lewandowski, \& Templin, 2010; Kira et al., 2015; for meta-analysis see: Pascoe \& Richman, 2009; Schmitt, Branscombe, Postmes, \& Garcia, 2014). Further, discrimination may negatively affect performance through stereotype threat, among other dynamics (e.g., Steele \& Aronson, 1995).

While the negative mental health effects of discrimination are well documented, the mechanism of action and pathways to such effects, especially in gender discrimination (GD) are not empirically explored. The goal of the current project is to empirically test a conceptual model that identifies some of these pathways which operate in producing the negative mental health outcomes of GD.

There is evidence that GD's negative mental health effects are salient across cultures with a potential doseresponse and cumulative dynamics (Kira et al., 2015). Most current measures of gender discrimination (GD), for example, Modern Sexism and old-fashion Sexism scales (Swim, Aikin, Hall, \& Hunter, 1995), the Schedule of Sexist Events (Klonoff \& Landrine, 1995), Patriarchal Beliefs Scale (Yoon et al., 2015), and the Ambivalent Sexism Inventory (Glick \& Fiske, 1996) are limited on their scopes. While they may provide frameworks for some gender discrimination dynamics, they lack a comprehensive conceptual model of GD and coping dynamics that guided their construction, which makes them less useful in gender discrimination research. For example, they mostly lack the focus on the family as important on initiating and propagating GD horizontally and vertically across generations. Our arching goal in this project is to develop a comprehensive conceptual framework of GD, its dynamics and coping mechanisms and use it to develop parsimonious reliable and valid measures of GD and its coping dynamics that can be utilized to advance research on GD.

\subsection{Critique of Current Conceptualizations of Gender Discrimination (GD)}

While there is a growing movement toward gender equality in some advanced societies, severe gender discrimination is still practiced even within some sub-cultures in those advanced societies. GD is deeply rooted in most cultures and has been, for long, masked, ignored or denied by some social knowledge structures, as chronic traumatic stress enacted by social power dynamics which is deeply rooted and cross-generationally transmitted across cultures and history (e.g., Fouad et al., 2000; Kira et al., 2015). One potential reason for avoiding the right characterization of GD as chronic traumatic stress (this may apply for all other discriminations and severe inequalities as well), is that some of our dominant knowledge structures are, or used to be, intricate parts of such social power dynamics that produce such discriminations in the first place (e.g., Fouad et al., 2000; Kira et al., 2015; Schmitt, 2015). Due to such historical denial of GD as continuous traumatic stress related to female's identity, our understanding of such discrimination producing dynamics and the mechanisms of its negative effects is still relatively under-developed and produced inadequate measurement strategies of its components.

It is important to examine the concept of societal power dynamics to be able to understand discrimination and its effects. The implicit and explicit power differentials may yield favorable position to one party (or group) and their members; with the assumption that this party has more innate stable and/or situational merits over the other. 
Such assumptions create stereotypes about both parties: the powerful and the fragile, which may reflect in self and social evaluation of each in terms of the relative status, feeling of identity threats, stereotype threat, and related perceived self-esteem and self-efficacy, as well as perpetuating social and cultural stereotypes that project itself on in the life course development and on mental and physical health and quality of life for both genders.

Societal power dynamics is often ignored inseparable parts behind different kinds of discriminations. However, power dynamics in the case of gender discrimination are entangled by the intimacy and close relatedness (attachments) involved in gender and family relations, which makes GD more complicated, as we will detail. Such entanglement may not exist in other types of discriminations. GDs, for this reason, are potentially more conducive to a feeling of betrayal. Betrayal in close relationships, especially by parents and care-givers, can be traumatic producing one of the most damaging mental health effects (e.g., Freyd, Klest, \& Allard, 2005).

\subsection{A Proposed Typology of GD}

There are two primary distinct but intersected cultural channels that may transmit and propagate the attitudes and behaviors that lead to and propagate GD: social institutions and direct family members (parents). Social, religious and social institutions may perpetrate GD systemic trauma (GD-S) while parents, family members and significant others (intra-household members) perpetrate (GD-P) betrayal trauma early on from birth and even in their pre-natal investments (Bharadwaj \& Nelson, 2012). Attitudes, beliefs and related cognitions and behaviors from parents and social institutions, that are cross-generationally transmitted, are often entrenched in cultural, social and religious norms (Kira, Lewandowski, Chiodo, \& Ibrahim, 2014; Kira et al., 2015).

It is important to measure GD on its different points of contact in the family and society. From a structural perspective, there are two sources or types of GD: GD perpetrated through interpersonal relations, and GD perpetrated by social and cultural institutions. The most critical kinds of interpersonal GD's behaviors and attitudes are perpetrated in the context of the close relationship, i.e. family and parents, which start early on in life and affect the trajectories of gender and personality development.

\subsection{A Traumatology/Oppression Conceptual Model of GD}

According to the traumatology perspective on gender discrimination (GD) (Kira et al., 2010, Kira, Ashby, Lewandowski, Smith, \& Odenat, 2012; Kira et al., 2015; Kira, Lewandowski, Chiodo, \& Ibrahim, 2014), GD is a serious continuous trauma for females that have been masked and rationalized across cultures and history. GD of females (and other types of discriminations) is an identity type III (continuous), and systemic trauma perpetuated by family and social systems and is one of the by-products of societal power dynamics. GD is one that is chronic and ongoing traumatization that may not stop and stick with the affected person all her/his life (as contrasted with Type I trauma (a single event or blow) and type II trauma which is a set of psychological sequelae that happened in the past and stopped). Type III identity traumas have potential of accumulation and proliferation dynamics and are potentially the most severe, in terms of its impact on health, mental health of the targeted individual and group (Kira, Ashby, Lewandowski et al., 2013).

Further, GD, as independent trauma that is expressed in implicit and explicit discriminatory attitudes, stereotypes, and behaviors that threaten the females' gender identity, can proliferate to different related or dependent traumas, such as, gender-based violence, intimate partner violence, stalking, sex trafficking, and prostitution which are some of the GD motivated social products. Further, GD, its independent and dependent related traumas can proliferate further and increase vulnerability to other trauma types that can spell over the life span. Gender discrimination, comprises of micro (e.g., implicit and explicit insults to identity status and exclusions that constitute identity threats) as well as macro aggressions (e.g., gender-based violence, trafficking, honor killing, rape, female genital mutilation, hate crimes) which additionally constitute secondary or vicarious traumas for other not directly affected females. GD may also intersect with other social oppressions and discriminations, such as socio-economic inequalities and relative deprivations, and ethnic and racial discriminations (e.g., Denton, \& Walters, 1999), which amplify its effects yielding linear and non-linear cumulative dynamics (Kira, Alawneh, Aboumediene, Lewandowski, \& Laddis, 2014). There is experimental evidence that threats to social identity can trigger social deviance, which was driven by the tendency to construe social identity threats not as isolated incidents but as symbolic of the continuing devaluation and disrespectful treatment of one's group (e.g., Belmi, Barragan, Neale, \& Cohen, 2015). Gender discrimination, subtle and blatant, is based, in such structures, on man's assumed/perceived superiority, control, and dominance over woman's identity on familial, social, political, religious and 
economic institutions.

\subsection{Gender Discrimination Dynamics}

\section{Self-Esteem and Self-Efficacy Dynamics}

It is important to examine the concept of societal power dynamics to be able to understand discrimination and its effects. The implicit and explicit power differentials may yield favorable position to one party (or group) and their members; with the assumption that this party has more innate stable and/or situational merits over the other. Such assumptions create stereotypes about both parties: the powerful and the fragile, which may reflect in self and social evaluation of each, in terms of the relative status, feeling of identity threats, stereotype threat, and related perceived self-esteem and self-efficacy, as well as perpetuating social and cultural stereotypes that project itself on in the life course development and on mental and physical health and quality of life for both genders.

Societal power dynamics (soft or extreme) are inseparable parts behind different kinds of discriminations. However power dynamics in the case of gender discrimination, as mentioned earlier, are entangled by the intimacy and close relatedness (attachments) involved in gender and family relations, which make GD more complicated. Such entanglement may not exist in other types of discriminations. GDs, for this reason, are potentially more conducive to a feeling of betrayal. Betrayal in close relationships, (e.g., by parents, can be traumatic producing negative mental health effects (e.g., Freyd, Klest, \& Allard, 2005).

GD, created by such power dynamics, tends to significantly lower the status of one gender and to elevate substantially the status of the other, inflating the dominant gender and deflating the subjugated gender identity and self-worth (esteem and efficacy), potentially hurting both genders. It was long observed that gender power differentials, entailed women to be more vulnerable to internalizing behavior, and men to be more impulsive and more vulnerable to externalizing behavior (and authoritarianism) (Kira et al., 2012; Kira et al., 2015; Rosenfield, Lennon, \& White, 2005; Kaufman, 2009). Inflated self-esteem of males may drive them for more risk-taking behavior, increases their higher status stress and make them more vulnerable to externalizing disorders and related health issues, while deflated self-esteem for females drive them or be more vulnerable to internalizing disorders and related health problems. While females are higher in morbidity, men are higher in mortality. Male death rates are higher than women's at all ages, and women report more symptoms, disability days, use of medications and physicians' visits than males (e.g., Arber \& Cooper, 1999).

Consistent with this framework, meta-analyses reported consistent finding that males have higher self-esteem than females (Kling, Hyde, Showers, \& Buswell, 1999; Major, Barr, Zubek, \& Babey, 1999). McMullin \& Cairney, (2004) reported that females have lower self-esteem across age groups from adolescence to old age and found that the declining trend of self-esteem in old age is steeper for females than males.

Self-esteem refers to a person's overall evaluation of his or her own worth and is regarded as an essential component of mental health (e.g. Mann, Hosman, Schaalma, \& de Vries, 2004). Research typically found a higher order core self-concept construct (CSC) comprises primarily of self-esteem and generalized self-efficacy (e.g., Johnson, Rosen, \& Levy, 2008) which thought to influence all other beliefs and bias appraisals, perceptions and emotions and actual behavior (Judge \& Bono, 2001). Reduced self-esteem and self-efficacy resulted from gender identity status and stereotype threats can be conducive to radical negative changes in emotion, cognition and behavior increasing vulnerability and decreasing resilience. Reduced self-esteem and self-efficacy in devalued identity situation became an automatic implicit latent self-schemas that negatively bias appraisal of events and stressors and perception of available internal and external resources, increasing vulnerability of females and other victims of discrimination (e.g., Steinberg, Karpinski \& Alloy, 2007; DeHart, Peña, \& Tennen, 2013). Implicit self-esteem and implicit self-efficacy are often defined as automatic self-evaluations.

Consistent with this conceptual framework of GD, meta-analyses of longitudinal studies found that lower self-esteem predicted the development and maintenance of internalizing disorders such as depression and anxiety (e.g., Sowislo \& Orth, 2013). Self-esteem and self-efficacy are among the important core of self-evaluations' traits that are correlated with emotional stability and locus of control, predicting job satisfaction, job-performance and educational attainment (e.g., Judge \& Bono, 2001; Orth, Robins, \& Widaman, 2012; Orth, Robins, Widaman, \& Conger, 2013; Trzesniewski et al., 2006).

Further, social identity threats can trigger existential anxieties affecting different aspects of functioning and self-cognitions and emotional responding. Social identity threats, as in the case in GD, have been shown to undermine performance (Steele \& Aronson, 1995), cognitive flexibility (Carr \& Steele, 2010), and willpower and 
can spillover to eating, decision-making and attention (Inzlicht \& Kang, 2010). They can also lead to social deviance (Belmi, Barragan, Neale, \& Cohen, 2015). People, when they feel devalued, tend to act impulsively (Gino et al., 2011) and anti-socially (Gibbons et al., 2012; Kamans, Gordijn, Oldenhuis, \& Otten, 2009).

\subsection{Dynamics of Coping to GD}

While the GD is severe chronic traumatic stress that impair or injure female's identity and may trigger existential anxiety, females' coping response to it tends to vary. One of the primary potential responses is that the female may hate her gender (alienation and internalizing a stigma of being a second class gender) wishing to be a male to gain a more favorable status and to belong to the superior gender. This response may create self-dissatisfaction and gender identity conflict and/or internalized stigma of her gender. This gender identity conflict, or internalized gender stigma may not be related to gender dysphoria which is biologically rather than socially-based, but can feed into it. Another potential response is to accept and internalize her second class status and act according to it. Internalization of the pervasive male-centered norms of women's objectification may minimize their competence, and deny them their agented qualities and negatively affect their performance (Quinn, Kallen, Twenge, \& Fredrickson, 2006). Some members of the same disadvantaged group, to cope with distress related to GD, disapprove an individual who claims or emphasizes GD (Garcia et al., 2010). Indeed many females especially in traditional cultures, unable to deal with unstoppable identity violations, turn to a kind of dissociated state and deny experiencing discrimination even in the face of objective indicators to the contrary (e.g., Crosby, 1984). A motivation to justify the unjust GD may lead individuals to endorse explanations that portray gender differences as stemming from deep, innate natural causes (Brescoll, Uhlmann, \& Newman, 2013). System justification theory suggests that people have an essential motive to view their social system as just, fair, and good and will engage in different strategies to justify the status quo (Jost, Banaji, \& Nosek, 2004; Sidanius \& Pratto, 1999, Yeung, Kay, \& Peach, 2014).

The third type of female's potential coping strategy is to resist such powerful dominant structures and attitudes that impose a secondary status for her gender. Resistance to GD, even it is potentially stressful, is assumed to relatively protect self-esteem and efficacy and reduce vulnerability to internalizing disorders while the first and second potential GD coping strategies stem from and/or end up to deflated self-esteem and self-efficacy. Stereotypes threats accepted by the first and second responders may lower their performance and efficacy while the resistance displayed by the third coping strategy may protect self-esteem and self-efficacy of the resistant females. These three coping strategies mediate/moderate the effects of GD and the related self-worth and efficacy on mental and physical health. Such GD coping strategies have never been operationalized, measured or empirically examined.

Figure 1 delineates the traumatology-based conceptual model of GD with its components and dynamics that we discussed. It describes GD effects on mental and physical health variables as mediated by self-esteem, self-efficacy and moderated by GD three coping strategies.

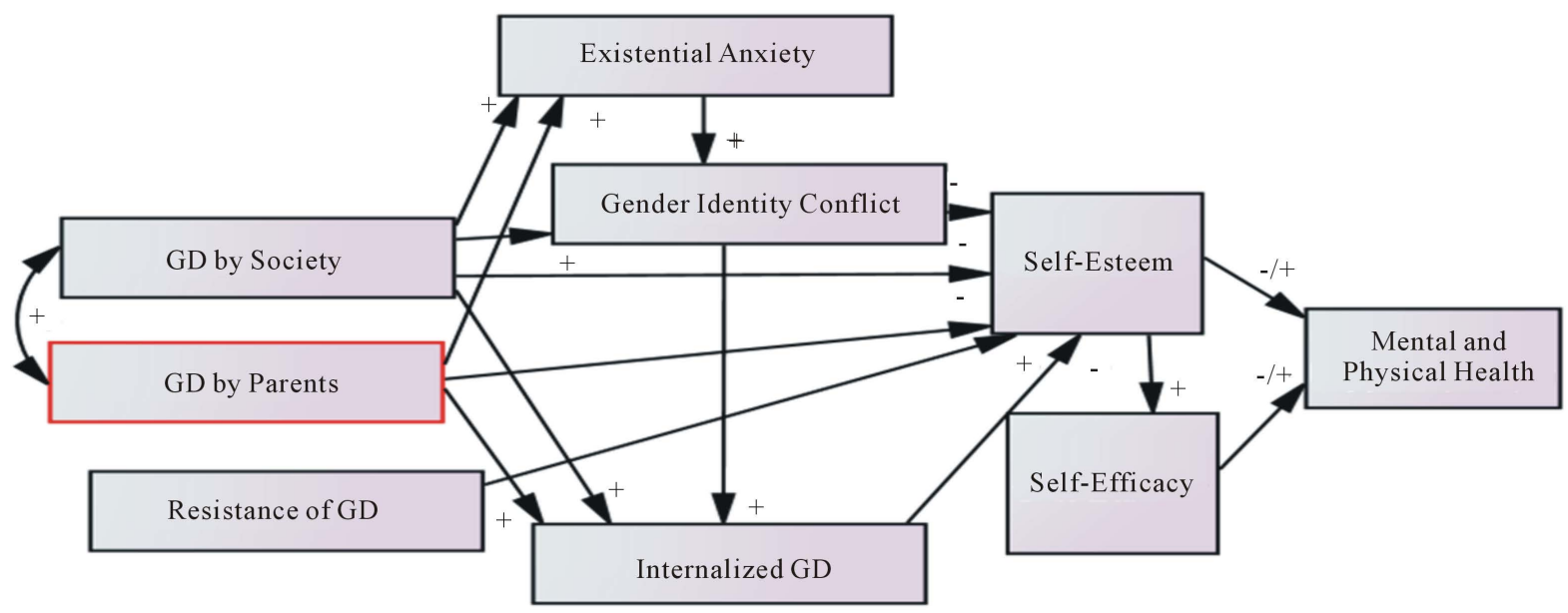

Figure 1. A graphical presentation of the conceptual model of gender discriminations (GD) dynamics. 


\subsection{The Goals of Current Project}

The goal of the current study is to utilize the proposed conceptual framework of GD and related dynamics to develop measures of its different components and test the reliability, the structural and predictive validity of their scores. GD components, that we intend to measure, include the different types of gender discrimination (GD-P and GD-S), and of GD coping strategies (i.e., gender identity conflict, internalizing GD, and GD resistance). The conceptual model basic assumptions will be used to determine the developed measures scores predictive validity. The GD conceptual framework predicts that gender-related self-esteem and self-efficacy mediate GD negative effects on mental health (e.g., Kira et al., 2015). Additionally, the three coping strategies with GD (gender identity conflict (or internalized gender stigma), internalized GD, and GD resistance) would moderate its effects.

Within the scope of this project, we conducted two studies, the first was on a sample of 150 female college students, on which we performed factor analysis to test the proposed structure and eliminate the items that are less significant and evaluate the assumption of the linear and non-linear relationship between GD variables and self-esteem and efficacy and PTG. The second study utilized a sample of 311 female college students to improve on the measures and to test their structural validity using confirmatory factor analysis. In the second study, in addition to self-esteem and self-efficacy, we measured, post-traumatic stress disorder (PTSD), cumulative trauma disorders (complex PTSD) (CTD) and existential annihilation anxiety (AA) and conducted path analysis to test the GD and it coping strategies' interpreted scores predictive validity.

\section{Method}

\subsection{Procedures of the Two Studies}

All questionnaires were administered to participants during the winter and the spring of 2015. The participation was voluntary. Each participant informed about the general goals of the study and signed informed consent to participate. Each person took between 40 - 50 minutes to complete the questionnaire in each study. The University IRB previously approved the research as part of a comparative study between Egyptian and USA students.

\subsection{Scientific Translation of the GD Inventory (GDI)}

The GD inventory and its sub-scales were translated to Arabic according to guidelines for translating psychological tests (van de Vijver \& Hambleton, 1996). The committee of translators consist of three bilingual Egyptian professionals whose native language was Arabic and working in English department in South Valley University. Each translated the scale independently with from English to Arabic. The translations were compared until an agreement is reached on an optimal translation. Back translation was conducted independently by a different-two bilingual professional. The back translators have expertise in psychology and linguistics. The best back-trans- lated version of the scale was compared to the original English language version for linguistic equivalence.

The other utilized measures were previously translated following the same procedure. Further, these measures proved to have adequate reliability and validity in Arabic clients in previous studies as will be briefly described when introducing them in the measures section.

\section{Study One}

\subsection{Participants}

The current study uses a convenient sample where the participants were recruited from the population of students taking an undergraduate course who agreed to participate in the study. The sample included students enrolled in South Valley University, Qina, Egypt with varieties of majors (Nursing, Education, Arts and Humanities, and sciences). The entirely accessible population was invited to participate in the study, $85 \%$ of those who were invited agreed and consented to participate. One hundred and fifty students participated in the study. All of the students were female. Participants were from all different class levels: freshmen (13.3\%), sophomores (13.3\%), juniors (62\%), and seniors (11.3\%). The majority of the respondents were under the age of $20(56 \%, n=84)$, and $26.7 \%(n=40)$ of the respondents were the age of 21 . The rest $(17.3 \%, n=26)$ were the age of 22 . Table 1 provides summary statistics of the two samples. 
Table 1. Characteristics of participants in the two studies.

\begin{tabular}{|c|c|c|c|}
\hline Variable & Sample distribution & $\underset{\%}{\text { First Study } N}=150$ & $\underset{\%}{\text { Second Study } N=311}$ \\
\hline \multirow{3}{*}{ Age } & Under $\leq 20$ & 56 & 57.1 \\
\hline & 21 & 26.7 & 18.8 \\
\hline & $22-24$ & 17.3 & 24.1 \\
\hline \multirow{3}{*}{ Academic standing } & Freshmen \& Juniors & 75.3 & 42.1 \\
\hline & sophomores & 13.3 & 17.4 \\
\hline & senior & 11.3 & 40.5 \\
\hline \multirow{4}{*}{ Major } & Arts \& Humanities & 24.7 & 24.1 \\
\hline & Education & 13.3 & 24.1 \\
\hline & Nursing & 48.7 & 27.7 \\
\hline & Sciences & 13.3 & 24.1 \\
\hline \multirow{2}{*}{ Religion } & Muslim & 96 & 96.5 \\
\hline & Christian & 4 & 3.5 \\
\hline \multirow{2}{*}{ Residence } & Village & 64 & 64.3 \\
\hline & Town & 36 & 35.7 \\
\hline \multirow{4}{*}{ Health Status } & Very good & 48 & 38.9 \\
\hline & Good & 52 & 58.5 \\
\hline & Poor & 0 & 2.3 \\
\hline & Very poor & 0 & 0.3 \\
\hline \multirow{3}{*}{ Income level } & Low & 1.3 & 1 \\
\hline & Average & 91.3 & 87.1 \\
\hline & High & 7.3 & 11.9 \\
\hline
\end{tabular}

\subsection{Measures}

\section{Development of GD Inventory}

Procedures of Measuring GD components, and GD coping strategies:

Measuring GD involves different operationalized thematic components that include: GD by parents, GD by others than parents and by societal and political institutions, the interrelated gender identity conflict (or internalized stigma of gender identity) (GIC), and internalizing GD (IGC), as well as GD resistance (GDR). These components involve attitudes/beliefs, stereotypes as well as discriminatory behaviors. To measure these thematic constructs, we developed a pool of 101 items that represent the identified constructs. We included items from some previous measures, e.g., the schedule of sexist events (Klonoff \& Landrine, 1995), and Patriarchal Beliefs Scale (Yoon et al., 2015). There were no measures we know for GD by parents, IGD, GIC, GIR constructs for which we developed more items. The research team carried careful examination of the 101 items and ended up in keeping only 75 items, represented the six main conceptual components, to be included in the analysis (26 items eliminated as the deemed to be weak or redundant) to be included in the analysis.

The six conceptual components include GD by parents attitudes, (example items are "My father prefer to have boys", “One of my parents has/had negative attitudes toward me due to my gender". The second component is GD by parents discriminatory behavior (example item is: "My parents put limitations and more control on my using the internet and/or the mobile phone, that they do not put on boys"). The third component is GD by others and society and includes items from life-time occurrence of the schedule of sexist events (Klonoff \& Landrine 
1995). An example item is: "How many times have you been treated unfairly by strangers because you are a woman?” A fourth component is Gender identity conflict (or internalized stigma of female gender identity). Example items are "I would rather be a boy if I could", I wish I were a boy", and "I am disappointed in myself because I am a female". The fifth component is IGD. An example item is "I tend to be manageable/easy (surrender) because I am a female". The sixth dimension is GIR. It included items such as "I am a feminist who fights against gender discrimination and the injustice".

The participant was instructed for all items (except for the schedule of sexist events subscales items that we retained at this step its original instructions) to rate her agreement/disagreement of the statement on a scale of 1 5, with I means strongly disagree, and 5 means strongly agree. For GD by others and society subscale (the schedule of sexist events modified), the instruction, as in the original scale, asked the participant to think carefully about how her life (from when she was a child to now) has been like as she answers the questions on a scale from 1 - 6, with 1 means the event has never happened to her, and 6 means the event happened almost all of the time (more than $70 \%$ of the time).

In addition to Gender Discrimination Inventory (GDI), we used Arabic versions of the following measures that were available from their original authors after their translations were reviewed by the committee of translators and found accurate and appropriate for the population.

General Self-efficacy Scale (GSE) is a 10-item scale (Schwarzer \& Jerusalem, 1995) designed to assess positive self-beliefs used to cope with a variety of life demands. The scaled score for each question ranges from 1 to 4. Higher scores indicate a stronger belief in self-efficacy. The scale was found to be configurally equivalent across 28 nations, and it forms only one global dimension (e.g., Scholz, Dona, Sud, \& Schwarzer, 2002). Cronbach alpha ranges from 0.75 to 0.94 across a number of different language versions (e.g., Luszczynska, Scholz, \& Schwarzer, 2005). Relations between the GSE and other social cognitive variables (intention, implementation of intentions, outcome expectations, and self-regulation) are high and confirm the validity of the scale (Luszczynska et al., 2005). Its alpha reliability in the current data is .85.

The Rosenberg self-esteem scale (RSES) (Rosenberg, 1965) is a 10-item scale that measures global self-esteem. Each item is rated on a 4-point Likert-type scale from strongly agree to strongly disagree and scored from $0-3$. The scale is divided by five positively worded and five negatively worded statements. The RSES has been translated and adapted to various languages including Arabic. Rosenberg reported good psychometrics for the scale and its reliability ranging from .85 to .88 . For the current Arabic sample alpha was .75 .

\subsection{Analysis}

Data were analyzed utilizing IBM-SPSS 22, as well as Amos 22 software. To determine the GD scales interpreted scores structural validity and their factor structures, exploratory Factor Analysis (EFA) principal axis factoring (PAF) were performed. The application of principal component analysis (PCA) against PAF has been hotly debated (e.g., Costello \& Osborne, 2005; Henson \& Roberts, 2006). Because, the goal of the current analysis is to arrive at a parsimonious representation of the associations among measured variables, and not data reduction, PAF (Principal Axis Factoring) is more appropriate than PCA (principal components analysis). Varimax orthogonal rotations technique was used as we assumed that some of the scales' components may be independent; however, because some of the measures may not be independent we conducted Oblique rotation (Oblimin), using delta value of (0) which is the default value of Oblimin procedure in SPSS, and compared the results. We used scree test (Cattell, 1966) and parallel analysis (O'Connor, 2000) to help determine the number of factors, as well as the a priori conceptual assumptions discussed in the introduction that set six a priori components.

Further, zero order correlation analysis was conducted to determine if there are significant relationships between GD variables and self-esteem and global self-efficacy.

\subsection{Results}

\subsubsection{Initial Structural Validity: Exploratory Factor Analysis (Principal Axis Factoring)}

To test the structural validity of the GD's proposed conceptual model, we conducted Principal Axis Factoring (PAF). The Kaiser-Meyer-Olkin measure of sampling adequacy was .779, above the commonly recommended value of .6 , and Bartlett's test of Sphericity was significant $\left(\chi^{2}=1958.52\right.$, d.f. $\left.=528, p<.000\right)$. The diagonals of the anti-image correlation matrix were also all over .5. Finally, the communalities were all above .3 (see Table 2), 
Table 2. Factor loadings and communalities for GD items in study 1 using principal axis factoring, with oblimin rotation and kaiser normalization.

\begin{tabular}{|c|c|c|c|c|c|c|c|}
\hline \multirow{2}{*}{ Items } & \multicolumn{6}{|c|}{ Factors } & \multirow{2}{*}{ Communalities } \\
\hline & 1 & 2 & 3 & 4 & 5 & 6 & \\
\hline My father prefers to have boys. & .81 & -.11 & .18 & .06 & .08 & .01 & .664 \\
\hline My mother prefers to have boys. & .70 & .04 & .03 & .04 & .03 & .05 & .635 \\
\hline My family generally prefers boys. & .69 & .06 & .12 & .04 & .01 & .05 & .655 \\
\hline $\begin{array}{l}\text { I have been told by some family members } \\
\text { that girls have less worth than boys. }\end{array}$ & .61 & .16 & .16 & .15 & .05 & .05 & .635 \\
\hline $\begin{array}{l}\text { One of my parents has/had negative } \\
\text { attitudes toward me due to my gender. }\end{array}$ & .49 & .23 & .01 & .02 & .12 & .03 & .572 \\
\hline $\begin{array}{l}\text { One of my parents (or both parents) } \\
\text { neglected me because I am a girl. }\end{array}$ & .40 & .34 & .13 & .03 & .04 & .03 & .577 \\
\hline $\begin{array}{l}\text { How many times have you been made fun } \\
\text { of, picked on, pushed, shoved, hit, or } \\
\text { threatened because of your gender. }\end{array}$ & .03 & .70 & .12 & .012 & .03 & .06 & .486 \\
\hline $\begin{array}{l}\text { How many times have you heard people } \\
\text { making sexist jokes, or degrading sexual } \\
\text { jokes. }\end{array}$ & .12 & .58 & .13 & .13 & .02 & .06 & .431 \\
\hline $\begin{array}{l}\text { How many times have people failed to } \\
\text { show you the respect that you deserve. }\end{array}$ & .07 & .54 & .08 & .00 & .06 & .40 & .513 \\
\hline $\begin{array}{l}\text { How many times have you wanted to tell } \\
\text { someone off for being sexist. }\end{array}$ & .20 & .50 & .04 & .16 & .05 & .07 & .516 \\
\hline $\begin{array}{l}\text { How many times have you been treated } \\
\text { unfairly by strangers because you are a } \\
\text { woman. }\end{array}$ & .06 & .47 & .05 & .05 & .04 & .07 & .386 \\
\hline $\begin{array}{l}\text { How many times have you been really } \\
\text { angry about something sexist that was } \\
\text { done to you. }\end{array}$ & .10 & .46 & .14 & .15 & .18 & .16 & .457 \\
\hline $\begin{array}{l}\text { How many times have you been called a } \\
\text { sexist name like bitch, cunt, chick, or other } \\
\text { names. }\end{array}$ & .01 & .44 & .09 & .05 & .12 & .09 & .346 \\
\hline $\begin{array}{l}\text { How many times have you been treated } \\
\text { unfairly by neighbors because you are a } \\
\text { woman. }\end{array}$ & .04 & .40 & .01 & .07 & .24 & .08 & .386 \\
\hline $\begin{array}{l}\text { I am disappointed in myself because I am a } \\
\text { female. }\end{array}$ & .10 & .08 & .82 & .10 & .04 & .08 & .724 \\
\hline $\begin{array}{l}\text { I would rather be a boy if I could', I wish I } \\
\text { were a boy. }\end{array}$ & .06 & .09 & .69 & .16 & .11 & .08 & .652 \\
\hline $\begin{array}{l}\text { If I have a choice, I would rather not to be } \\
\text { born at all as a girl. }\end{array}$ & .09 & .17 & .68 & .10 & .01 & .04 & .673 \\
\hline $\begin{array}{l}\text { Being a girl (not a boy or a man) has } \\
\text { spoiled my life. }\end{array}$ & .10 & .00 & .53 & .07 & .11 & .15 & .569 \\
\hline $\begin{array}{l}\text { Subtle and blatant acts of discrimination } \\
\text { because of being a female and against my } \\
\text { gender make me angry. }\end{array}$ & .08 & .08 & .09 & .65 & .04 & .00 & .437 \\
\hline $\begin{array}{l}\text { I am a feminist who fight against gender } \\
\text { discrimination and the injustice. }\end{array}$ & .04 & .16 & .11 & .53 & .05 & .22 & .507 \\
\hline $\begin{array}{l}\text { My parents put limitations and more } \\
\text { control on my using the internet and/or the } \\
\text { mobile phone, that does not put on boys. }\end{array}$ & .08 & .07 & .17 & .02 & .71 & .02 & .574 \\
\hline
\end{tabular}




\section{Continued}

My Parents give/gave more freedom to my brother/s in choosing what cloth to buy, because I am a girl.

My parents trust more and give greater liberty to boys than girls in choosing their friends.

My parents trust more and give greater liberty to boys than girls in choosing their education and career paths.

My parent set stricter curfew time on me compared to my brother/s.

My parents trust more and give greater liberty to boys than girls in choosing their future spouse.

I tend to be manageable/easy (surrender) because I am a female.

Because I am a girl, I need others to make at least some decisions for me.

I do not believe that women have suffered any real "injustices" throughout history.

\begin{tabular}{|c|c|c|c|c|c|c|}
\hline .10 & .03 & .15 & .13 & .59 & .11 & .412 \\
\hline .02 & .04 & .06 & .00 & .55 & .04 & .406 \\
\hline .07 & .00 & .18 & .42 & .51 & .15 & .542 \\
\hline .20 & .04 & .07 & .04 & .42 & .12 & .427 \\
\hline .12 & .29 & .23 & .09 & .40 & .05 & .365 \\
\hline .05 & .00 & .12 & .10 & .04 & .58 & .393 \\
\hline .05 & .12 & .27 & .11 & .10 & .42 & .422 \\
\hline .02 & .27 & .04 & .31 & .14 & .41 & .340 \\
\hline 8.46 & 2.89 & 2.12 & 1.89 & 1.69 & 1.56 & \\
\hline 23.49 & 8.04 & 5.89 & 5.26 & 4.68 & 4.33 & \\
\hline
\end{tabular}

further confirming that each item shared some common variance with other items. Given these overall indicators, factor analysis was deemed to be suitable.

Principal axis factoring (PAF) analysis was used as it is favored over PCA as was discussed earlier, to test the structure validity of the constructs. Based on the factor and thematic analysis, we eliminated items that loaded less than .4 in initial factor solution and reanalyzed the retained items (33). Initial Eigen values indicated that the first six factors explained $23.28 \%, 8.28 \%, 6.23 \%, 5.67 \%, 4.86 \%$, and $4.72 \%$ of the variance respectively. The six-factor solution, which explained $53.04 \%$ of the variance, was preferred because of: 1 ) its previous theoretical support; 2) the "leveling off" of Eigen values on the scree plot after six factors; and 3) the insufficient number of primary loadings and difficulty of interpreting the seventh factor and subsequent factors. The six factors exceeded the 95th percentile of eigenvalues of factors derived from random data using parallel analysis (O'Connor, 2000). There was little difference between the six factor Varimax and Oblimin solutions, thus both solutions were examined in subsequent analyses before deciding to use an Oblimin rotation for the final solution because of its consistent loading and the assumption of correlated structures.

A total of four items were eliminated because they did not contribute to a simple factor structure in the rotated factors and failed to meet a minimum criteria of having a primary factor loading of .4 or above, and no crossloading of .3 or above. The items: "As a girl/a woman I feel somewhat naturally less compared to boys/men.," and "One of my parents discriminated against me because of my gender," and "My parents have been physically disciplined me more than my boy sibling/s.", and "How many times were you denied a raise, a promotion, tenure, a good assignment, a job, or other such thing at work that you deserved because you are a girl/woman?”, are the four items that did not load .4 or above on any factor.

In the final analysis, the Oblimin rotation provided the best defined factor structure. All items in this analysis had primary loadings over .4. Only one item had a cross-loading above .3 (My parents trust more and give greater liberty to boys than girls in choosing their education and career paths.), however this item had a strong primary loading of .51, and the cross loading is negative (-.41). The first factor (6 items) represents the discriminatory attitudes of parents and labeled: Gender discrimination by parents' attitudes (GD-Pa). The second factor $\mathrm{t}$ (8 items) represents discriminatory behavior by others than parents in society (GD-S), and is largely derived from the schedule of sexist events scale (Klonoff \& Landrine, 1995). The third factor (4 items) represent gender identity conflict (GIC) or gender stigma. The fourth factor (2 items) represents gender discrimination resistance 
(GDR). The fifth factor (6 items) represents gender discrimination by parents' specific behaviors (GD-Pb). The sixth factor (3 items) represents internalized GD (IGD). The factor loading matrix of final solution is presented in Table 2, while Table 3 presents inter-correlations between the six factors.

Internal consistency for each of the scales was examined using Cronbach's alpha. The alphas were moderate: .68 for GDR (2 items), fair for IGD: .60, good for GD-Pa: .83, for GD-S (8 items): .77, for GIC (4 items): .85, and GD-Pb (6 items): .75. GD total scale (GD-Pa + GD-Pb + GD-S) (20 items) has an alpha of .85, and GD-P total (13 items) is .85. No substantial increases in alpha for any of the scales could have been achieved by eliminating more items.

Descriptive statistics is presented in Table 4. Most of skewness and kurtosis statistics were well within a tolerable range for assuming a normal distribution and examination of the histograms suggested that the distributions looked approximately normal.

Table 3. Factor correlation matrix.

\begin{tabular}{|c|c|c|c|c|c|c|}
\hline Factor & 1 & 2 & 3 & 4 & 5 & 6 \\
\hline 1 & 1.000 & . & & & & \\
\hline 2 & .286 & 1.000 & & & & \\
\hline 3 & -.356 & -.208 & 1.000 & & & \\
\hline 4 & -.052 & .076 & .105 & 1.000 & & \\
\hline 5 & .419 & .127 & -.249 & -.034 & 1.000 & \\
\hline 6 & .171 & .109 & -.119 & -.088 & .094 & 1.000 \\
\hline
\end{tabular}

Note: Extraction Method: Principal Axis Factoring. Rotation Method: Oblimin with Kaiser Normalization.

Table 4. Initial statistics of the measures included in GD inventory in the two studies.

\begin{tabular}{|c|c|c|c|c|c|}
\hline \multicolumn{6}{|c|}{ Statistics in Study 1} \\
\hline & No. of items & $\mathrm{M}(\mathrm{SD})$ & Skewness & Kurtosis & Cronbach's $\alpha$ \\
\hline GD-Pa & 6 & $16.48(7.56)$ & .77 & -.44 & .83 \\
\hline GD-S & 8 & $22.89(8.46)$ & 1.34 & 2.49 & .77 \\
\hline GIC & 4 & $7.12(4.22)$ & 1.38 & .72 & .85 \\
\hline $\mathrm{GD}-\mathrm{Pb}$ & 6 & $16.28(6.50)$ & .59 & -.39 & .75 \\
\hline GDR & 2 & 7.65 (1.93) & -.76 & -.08 & .68 \\
\hline IGD & 3 & $8.78(3.55)$ & .58 & -.32 & .60 \\
\hline Total GD-P & 12 & $16.48(7.55)$ & .77 & -.44 & .84 \\
\hline Total GD (GD-Pa + GD-Pb + GD-S) & 20 & $39.37(14.00)$ & 1.17 & 1.41 & .85 \\
\hline \multicolumn{6}{|c|}{ Statistics in Study 2} \\
\hline GD-Pa & 7 & $16.47(6.42)$ & .46 & -.69 & .78 \\
\hline GD-S & 8 & $17.50(6.07)$ & 1.10 & 1.12 & .76 \\
\hline GIC & 4 & $6.31(3.32)$ & 1.53 & 1.57 & .84 \\
\hline GD-Pb & 6 & $18.26(6.90)$ & .48 & -.42 & .78 \\
\hline GDR & 4 & $6.56(2.80)$ & -.28 & -1.22 & .72 \\
\hline IGD & 4 & $9.84(3.82)$ & .31 & -.69 & .60 \\
\hline Total GD-P & 13 & $34.7(11.492)$ & .47 & -.30 & .84 \\
\hline Total GD (GD-P + GD-S) & 21 & $52.23(15.29)$ & .53 & .20 & .86 \\
\hline
\end{tabular}


Overall, the analysis indicated that six distinct factors were underlying participants' responses to the GD chosen items and that these factors were moderately internally consistent. Four of the all items were eliminated; however the original factor structure proposed by the developed conceptual model was retained. Each of the factors could probably be strengthened through revision (rewriting) items with lower primary loadings and possibly adding new items. This will be attempted in the Study 2.

\subsubsection{Initial Predictive Validity: Correlations Results}

Zero-order correlation results indicated significant negative correlations between GD-P, GD-S, total GD, GIC, and self-esteem and self-efficacy. Internalized GD was negatively correlated with self-efficacy, while resistance of GD was positively correlated with self-esteem. Table 5 presents a summary of these correlations.

\section{Study Two}

\subsection{Participants}

Participants: The sample included 311 undergraduate students enrolled in South Valley University (Qina, in upper Egypt), Egypt. The participants were recruited from the population of students taking an undergraduate course at the university.

All of the students were females. While the sample was mostly a convenience sample, we tried to represent all grades (freshmen, sophomores, and seniors) different majors (humanities and science). Of those invited 311 agreed to participate in the study (90\%). Table 1 summarizes the characteristics of the sample.

\subsection{Measures}

In addition to the Gender Discrimination Inventory’s Scales and sub-scales, self-esteem and self-efficacy measures we added the following measures in the second study

The Cumulative Trauma and Stress Scale CTS-S (short form) is a measure that is based on the DBTF framework (Kira, Lewandowski et al., 2008). The CTS-S is a 32-item instrument that measures cumulative trauma in terms of occurrence, frequency, type, and negative and positive appraisals. The measure identifies six trauma types: collective identity trauma, personal identity trauma, survival trauma, attachment trauma, secondary trauma, and gender discrimination. In response to each item on the measure, participants were instructed to indicate their experience with a traumatic event on a 5-point Likert-type scale ( 0 = never; 4 = many times). If participants endorsed that they had experienced the traumatic event, they were then asked to indicate the effect of the event on a 7-point Likert-type scale (1 = extremely positive; 7 = extremely negative). In the analysis, the appraisal scale was divided into two sub-scales: Positive appraisal (1 - 4) and negative appraisals (5 - 7). CTS-S includes two general scales for cumulative trauma dose, occurrence and frequency of experience, and two appraisal subscales, negative and positive appraisal of the events. The CTS-S has shown adequate internal consistency ( $\alpha$ = .85) (Kira et al., 2008; Kira, Fawzi, \& Fawzi, 2013), and test-retest stability (.84 in 6 weeks). CTS-S has been used with a variety of clinical and community samples of adults and adolescents from numerous sociocultural groups and has proven to possess adequate reliability (Alpha ranged between .80 and .92), good construct validity (e.g., Kira et al., 2008; Kira, Lewandowski, Somers, Yoon, \& Chiodo, 2012; Kira, Smith, Lewandowski,

Table 5. Zero order correlation between Gender discrimination Scales and Self-esteem and Self-efficacy (First Study).

\begin{tabular}{|c|c|c|}
\hline & Self-Esteem & General Self-Efficacy scale \\
\hline Discrimination attitudes by Parents Sub-scale & $-.33 * * *$ & $-.22 * * *$ \\
\hline Gender Discrimination by Society Sub-scale & $-.27 * * *$ & $-.20 * *$ \\
\hline Gender Identity Conflict Sub-scale & $-.36 * * *$ & $-.29 * * *$ \\
\hline Internalized Gender Discrimination Sub-scale & -.11 & $-.15^{*}$ \\
\hline Resistant of Gender discrimination Sub-scale & $.16^{*}$ & $.14+$ \\
\hline Gender Discrimination Behaviors by Parents Sub-scale & -.13 & -.12 \\
\hline Gender Discrimination by parents and society & $-.34^{* * *}$ & $-.24 * * *$ \\
\hline
\end{tabular}


\& Templin, 2010), and cross-cultural validity across different cultural and clinical groups including American Indians, Mayans, Palestinians, Egyptians, refugees, and torture survivors form 32 countries (e.g., Kira, Ashby, Odenat \& Lewandowski, 2013; Kira, Fawzi, \& Fawzi, 2013; Kira, Omidy, \& Ashby, 2014; Kira, Smith, Lewandowski, \& Templin, 2010; Millender, 2013). Alpha for the main scale of occurrence is .80 in the current data.

The Clinician-Administered PTSD Scale (CAPS-2) is a structured clinical interview that assesses 17 symptoms rated on frequency and severity on a 5-point scale. The CAPS has demonstrated high reliability, with a range from .92 - .99, and good convergent and discriminant validity (Weathers, Keane, \& Davidson, 2001). The instrument has four-factor subscales: re-experiencing, avoidance, arousal, and emotional numbness/dissociation. The measure contains two sub-scales: frequency and intensity. Elhai et al. (2006) found that the two sub-scales were highly inter-correlated (from .86 to .93) and were not differentially related to summed PTSD scores or PTSD diagnoses. In addition, Betemps, Smith, Baker, \& Rounds-Kugler (2003) discovered that the frequency format was associated with both greater reliability and item discrimination than the intensity format. The current study utilized the frequency subscale. CAPS-2 was administered through one-on one interview to all participants by trained fully licensed psychologists. The measure has an alpha of .91 in the current data.

Cumulative Trauma-related Disorders Measure (CTD) (Complex PTSD) (Kira, Templin, Lewandowski, Ashby et al., 2012). The 16-item scale was developed on five community and clinic samples of adults, adolescent Iraqi refugees, Arab Americans, and African Americans. It is an index measure that covers 13 different symptoms that includes memory deficits, loss of self-control, and somatization, dissociation, auditory and visual hallucinations, paranoid ideations, concentration and feeling suicidal. The score 0 indicates that the symptom not applicable, $1=$ not sure, 2 = somewhat present, 3 = present and 4 = very much present. Exploratory and confirmatory factor analysis found four factors: executive function deficits, suicidality, dissociation, and depression/anxiety/somatization comorbidity. It has good reliability (ranging from .85 and .98 in five different studies). Test-retest reliability in a 6-week interval was .76. The measure has good convergent, divergent, and predictive validity. Different kinds of traumas and cumulative trauma in general accounted for significant variance as predictors of CTD symptoms (Kira, Templin, Lewandowski, Ashby et al., 2012). The scale had an alpha coefficient of .86 in this study.

Annihilation (Existential) Anxiety Scale (AA) (Kira, Templin, Lewandowski et al., 2012) is based on the assumption that there are at least three main sources of the emergence of annihilation threats: personal identity, collective identity and threats from severe societal structural inequalities. Three items that represent the three components were used, for example, "because of what has happened to me personally or is happening to me personally, I sometimes worry that I just lose my sense of self (I worry that I will cease to exist as an individual person).” The answer was structured on a 5 point-Likert-scale (5. Strongly Agree; 4. Agree; 3. Not Sure; 2. Disagree; 1. Strongly Disagree). A score of 10 or higher indicates the presence of at least one kind of such concern about existence. The 3-item scale has been previously used on Iraqi refugees in Michigan and on three samples of Palestinians adults and adolescents, as well on the initial validation study on mental health clients $(\mathrm{N}=399)$. In the initial validation study, and following studies, its alpha reliability ranged between .90 - .95. Its convergent, discriminant and predictive validity was adequate (Kira, Templin, Lewandowski et al., 2012). In the validation study, using multiple regression, while all trauma types predicted AA, collective identity trauma was the highest predictor $(\beta=.74, p<.001)$. Negative appraisal of different survival and identity traumas was a stronger predictor of AA than just the occurrence of the traumas. AA was found to be a significant predictor of $\operatorname{PTSD}(\beta=.46, p<.001)$, cumulative trauma disorder (CTD) $(\beta=.43, p<.001)$, general anxiety $(\beta=.40, p<.001)$, depression $(\beta=.38, p$ $<.001)$, and poor self-rated health $\left(\beta=.14,{ }^{*} p<.01\right)$. Similar results were found in subsequent studies on Palestinians (e.g., Kira et al., 2012).

Posttraumatic Growth (PTG) single-item measure: "Every trauma that did not kill me makes me stronger." This single-item measure, drawn from Nietzsche's famous dictum "What doesn't kill me makes me stronger," has been used in research with torture survivors and refugees, as a measure of posttraumatic growth (Kira et al., 2006). Adding the item to the posttraumatic growth inventory PTGI 21 items (Tedeschi \& Calhoun, 1996) in a factor analysis, its communality was the highest (.899). It has an item loading of .95 in the rotated structure, and .88 in the pre-rotation component matrix. These results indicated high single-item reliability, according to the criteria for measuring single-item reliability proposed by Wanous \& Hudy (2001). It was significantly associated with the posttraumatic growth inventory, especially with internal growth dimension (Kira, Abou-Medien et al., 2012; Kira, Abou-Mediene et al., 2013). Test-retest reliability conducted, as part of the current study, on 
small sample of 30 college students, (after three weeks) is good (.956), which indicates excellent stability.

\subsection{Analysis}

Data were analyzed utilizing IBM-SPSS 22, as well as Amos 22 software. To determine the GD scales' structural validity and its factor structure scores, confirmatory factor analyses were conducted for the GD basic three scales (GD-S, GD-Pa and GD-Pb), and the three GD coping scales together (GIC, IGD, and GIR), then for the all the scales together, in addition to each scale separately, to see which one has the best fit of the data. Following Byrne's (2012) recommendations, the measurement model was evaluated to ensure an acceptable fit to the sample data. Criteria for good model fit were: a non-significant chi-square $\left(\chi^{2}\right)$, chi-square/degrees of freedom $\left(\chi^{2} /\right.$ d.f. $\left.>2\right)$, comparative fit index (CFI) values $>0.90$, root-mean-square error of approximation (RMSEA) values $<0.06$ (Weston \& Gore, 2006). The reliability of the scale was investigated with the Cronbach Alpha technique. Further, we investigated test-retest stability on small sample of 30 college students (with three weeks interval) for all the scales. Further, we conducted path analysis between the independent, dependent and mediating variables to test the measures predictive validity and the theoretical model outlined in the introduction, its variants and potential alternatives. We used the bootstrap procedure with 10,000 bootstrap samples to test the significance of direct, indirect and total effects and 95\% bias-corrected confidence intervals.

\subsection{Results}

\subsubsection{Construct Validity of GDI Scales and the GD Model}

Confirmatory factor analysis was conducted to test the construct validity of the GD model parameters and of each scale as a stand-alone measure. The analysis involved testing models fit for the three GD factors cluster separately (GD-S, GD-Pa, and GD-Pb), and then the three GD coping factors cluster (GIC, IGD, and GDR), and the model fit for each scale taken alone. Modification for the six-factors model (correlated errors between 10 items) did improve the CFI to reach an acceptable fit (fit indices for the six factor model after modifications: Chi Square $=770.713$, d.f. $=629, p=.000$, CFI $=.952$, RMSEA $=.027)$. Modifications of the three GD factors cluster (GD-S, GD-Pa, and GD-Pb) (correlated errors between 10 items) did improve the fit to an acceptable level (fit indices for the three-factor model after modifications: Chi Square $=450.445$, d.f. $=286, p=.000$, CFI $=.918$, RMSEA $=043)$. GD coping three-factors' model (GIC, IGD, and GDR) has good fit especially after modifications (correlated errors between 3 items) (Chi Square $=53.390$, d.f. $=47, p=.242$, CFI $=.992$, RMSEA $=021$ ). Further, we tested each scale separately; each scale model has a good fit. Figures 2-9 present all the confirmatory models.

\subsubsection{Predictive Validity of GDI Scales and the GD Model}

We analyzed alternative path models that approximate the conceptual model we proposed and those that fitted the data well. We chose to present this model, in which we introduced the cumulative trauma (other than GD) as independent variable to control for its effects. The model has Cumulative trauma, GD-P and GD-S as independent variables, GIC, IGD, GDR, self-esteem, self-efficacy, and post-traumatic growth as mediating/moderating variables and AA, CTD and PTSD as outcome variables. The model has good fit (Chi square $=43.187$, d.f. $=36$, $p=.191$, CFI $=.991$, RMSEA $=.025$ ). In this model Gender discrimination by parents GD-P (the combined two scales GD-Pa + GD-Pb) predicted directly increase in GIC, and IGD and directly and indirectly an increase in existential AA, and decrease in self-esteem. It predicted indirectly decrease in self-efficacy and increase in PTSD and CTD. GD by society (GD-S) predicted directly an increase in IGD and directly and indirectly an increases in AA and decrease in self-esteem. GD-S predicted indirect decrease in self-efficacy and an increase in CTD and PTSD. Post-traumatic growth (PTG) predicted directly an in increase in GDR, and directly and indirectly an increase in self-esteem and self-efficacy. PTG had positive direct effects on increased AA, and negative indirect effects on decreasing it, and its total effects on AA are not significant. GDR predicted indirectly small increase in AA and PTSD and to some extent on CTD. Resistance to GD against the mainstream seems to have its toll on the level of distress in this society. IGD predicted directly decrease in self-esteem and directly and indirectly decrease in self-efficacy. IGD predicted indirectly an increase in AA, and CTD. Self-esteem predicted directly an increase in self-efficacy, and decrease in AA. It predicted directly and indirectly a decrease in CTD. It indirectly predicted a decrease in PTSD. GIC directly predicted increased CTD and indirectly in PTSD. 


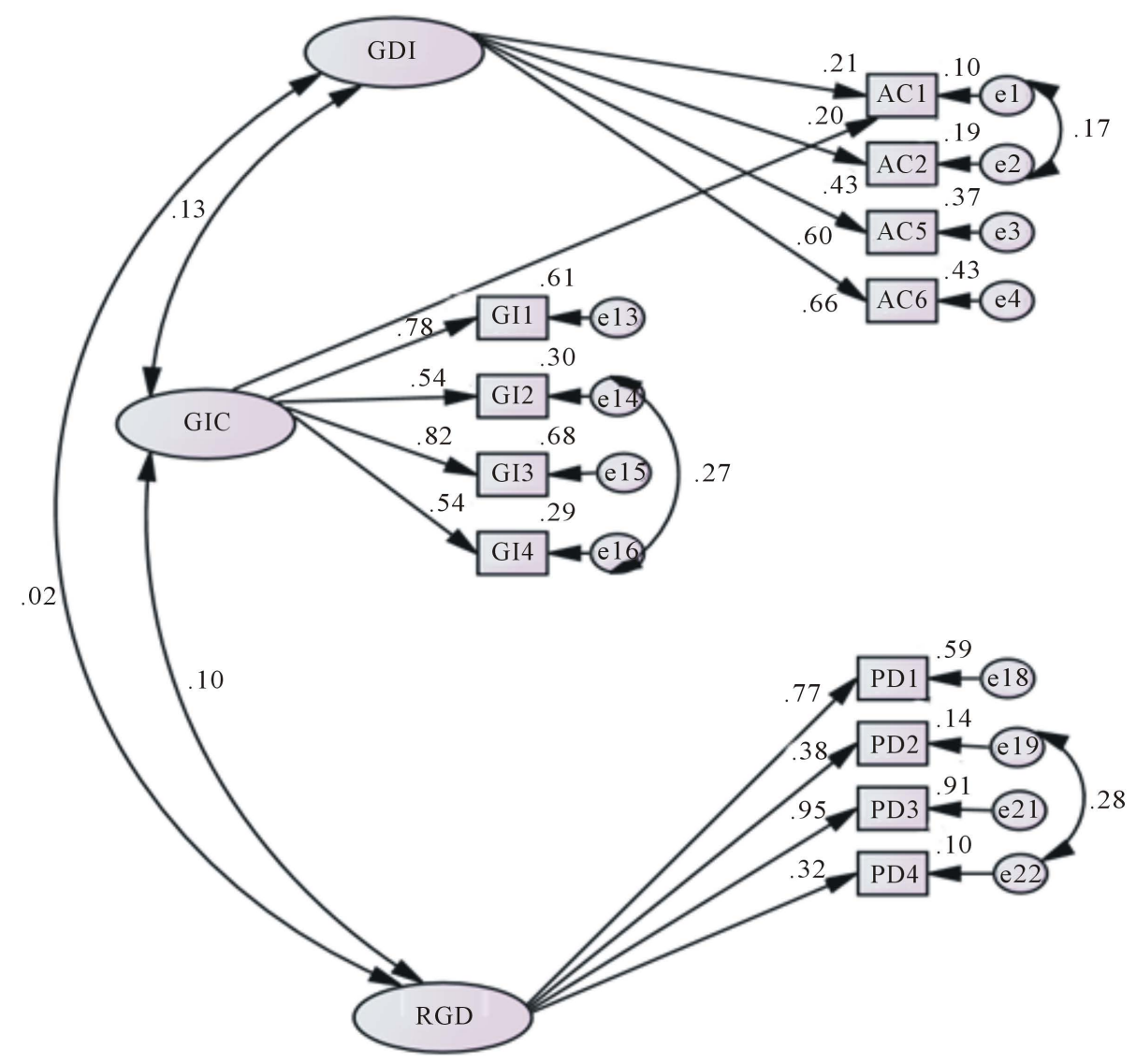

Figure 2. Confirmatory factor analysis for coping with GD three scales: gender identity conflict (gic), internalized gender discrimination (GDI) and gender discrimination resistance (RGD).

Self-efficacy predicted directly decreased CTD and indirectly decreased PTSD. Cumulative trauma (other than GD), AA, predicted increased CTD and PTSD. CTD accounted for the highest variance in the mode (squared R $=.433$ ). Figure 10 present the path diagram for the direct effects of the variables. Table 6 presents the direct, indirect and total effects of each variable and its 95\% confidence intervals.

\subsubsection{The Final GDI Scales}

The final GD and coping six scales are introduced in Appendix 1.

\subsubsection{Reliability of GDI Scales}

Test-re-test reliability was evaluated on a small sample $(\mathrm{N}=30)$ of college students with three weeks lapse. All the GD and GD coping scales showed excellent stability, with test-retest correlations ranged from.96 to .99. Alpha (internal consistency) reliability for the scales were as follows: GD Total = .86 (21 items), GD-S = .76 (8 items), GD-Pa = .78 (7 items), GD-Pb = .76 (6 items), GIC = .78 (4 items), GDR = .72 (4 items version), GDR $=.85$ ( 2 items version), GDR (4 items version Alpha = .76, and IGD = .60 (4 items), combined IGD and GDI (8 items) alpha is .74. 

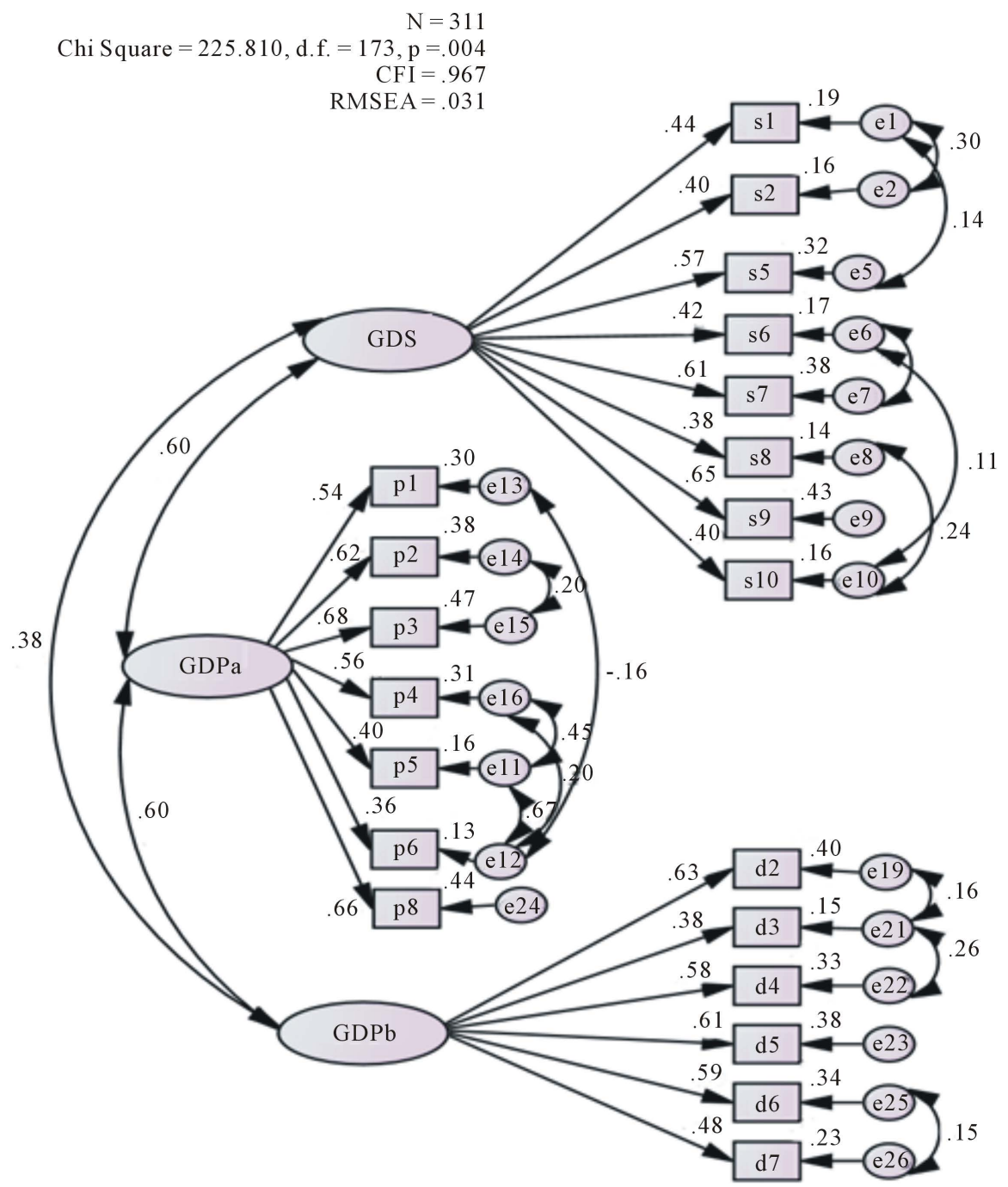

Figure 3. Confirmatory factor analysis for GD sub-scales (GD-S = GD by society, GD-Pa = GD by parents' attitudes, GD- Pb = GD by parents' specific behaviors).

$$
\begin{array}{r}
\mathrm{N}=311 \\
\text { Chi Square }=.589, \text { d.f. }=1, \mathrm{p}=.443 \\
\text { CFI }=1.000 \\
\text { RMSEA }=.000
\end{array}
$$

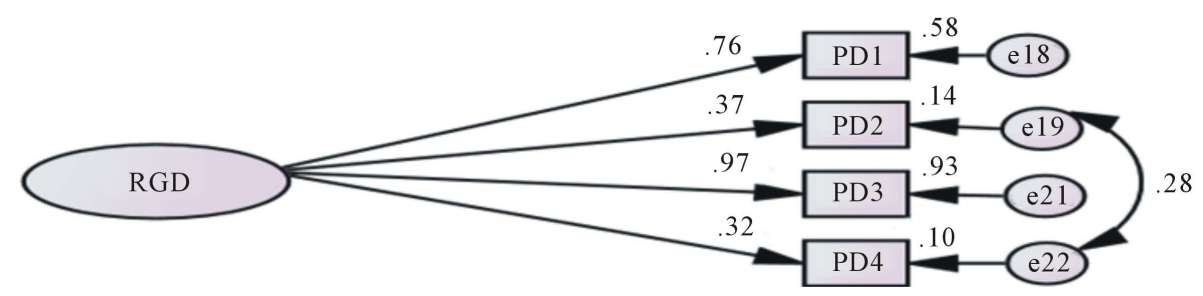

Figure 4. Confirmatory factor analysis for resistance of gender discrimination scale. 


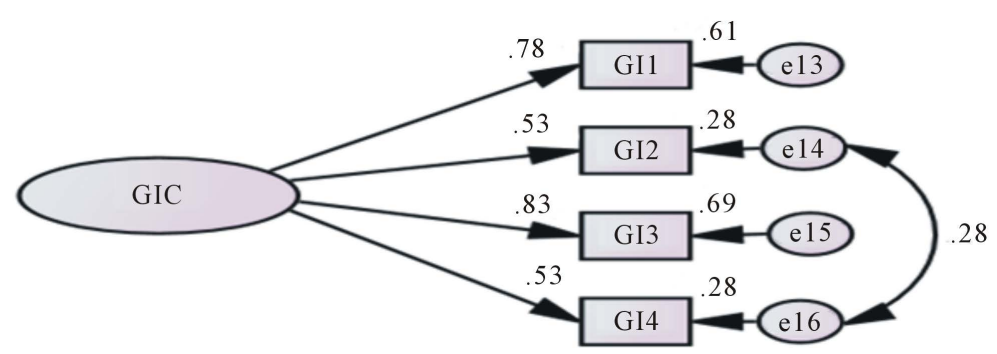

Figure 5. Confirmatory factor analyses for gender identity conflict scale.

$$
\begin{array}{r}
\mathrm{N}=311 \\
\text { Chi Square }=.687 \text {, d.f. }=1, \mathrm{p}=.407 \\
\text { CFI }=1.000 \\
\text { RMSEA }=.000
\end{array}
$$

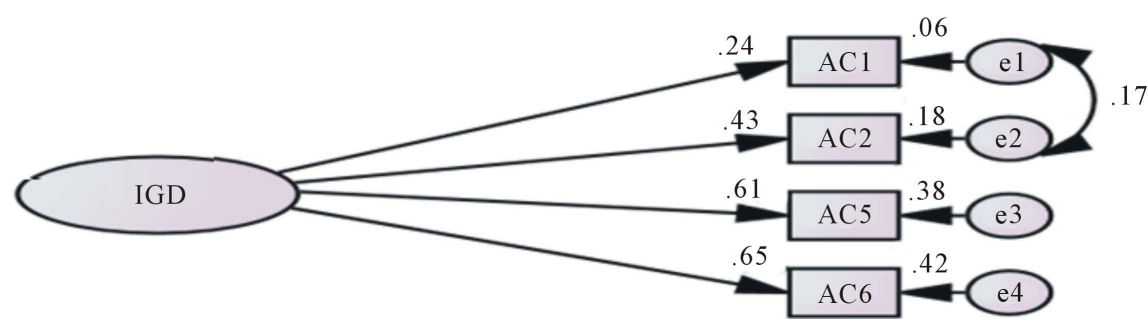

Figure 6. Confirmatory factor analysis for internalized gender discrimination scale.

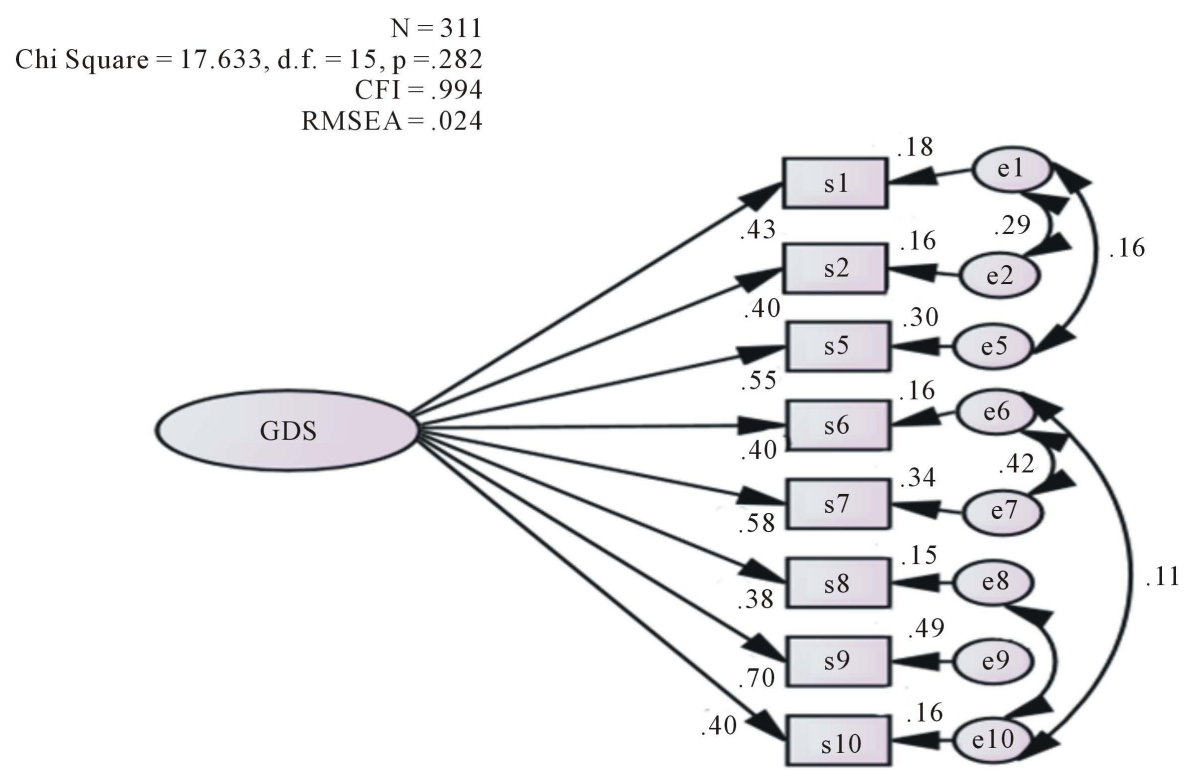

Figure 7. Confirmatory factor analyses for gender discrimination by society scale. 


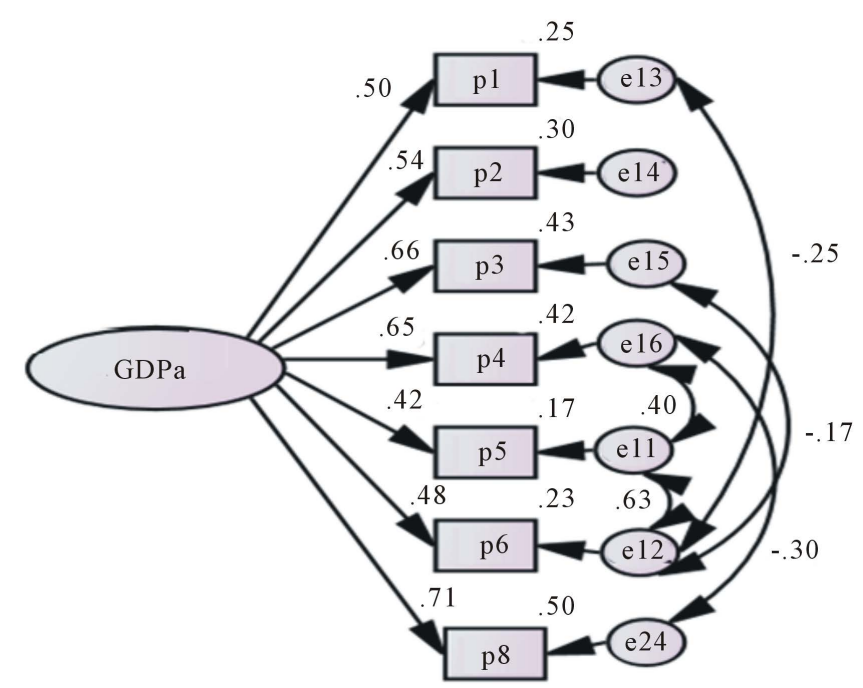

Figure 8. Confirmatory factor analysis for gender discrimination by parents’ attitudes.

$$
\begin{array}{r}
\mathrm{N}=311 \\
\text { Chi Square }=5.465 \text {, d.f. }=6, \mathrm{p}=.486 \\
\text { CFI }=1.000 \\
\text { RMSEA }=.000
\end{array}
$$

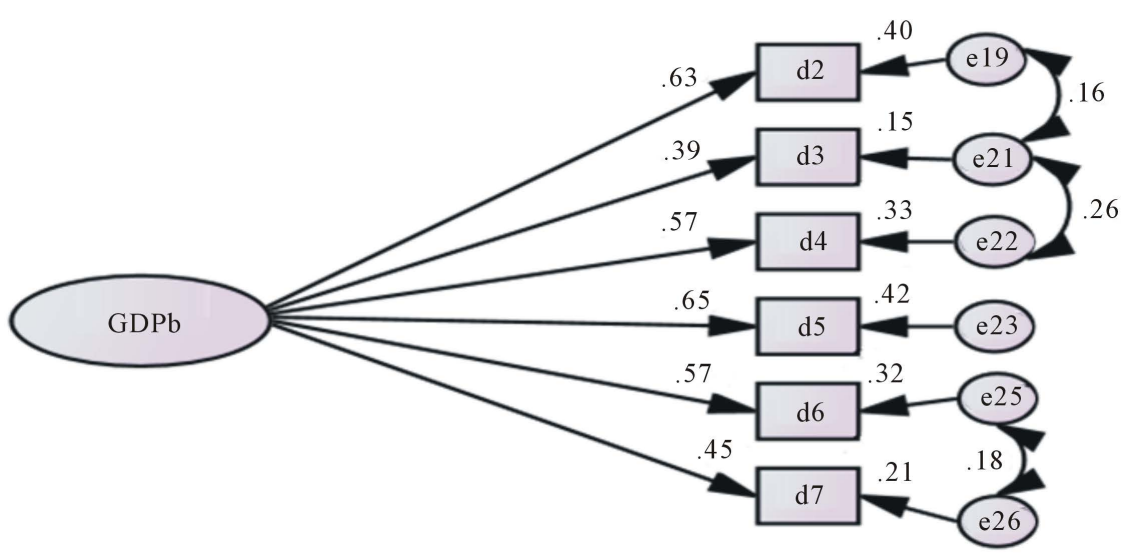

Figure 9. Confirmatory factor analysis for parents'gender discriminatory behaviors scale.

\subsubsection{Convergent Validity}

GD total score was highly correlated with the two items measure of GD in the CTS $(r=.40<.001)$. GD-S was highly correlated with the single item measure of discrimination by society in the CTS $(r=.37<.001)$. GD-P (total) was significantly correlated with the single item measure of discrimination by parents $(r=.32<.001)$. These results provided evidence of the scale convergent validity. Further, GD total score was highly correlated with other type III traumas (e.g., other discriminations) $(r=.40<.001)$, and personal identity trauma $(r=.31$ $<.001)$ and cumulative trauma $(\mathrm{r}=.38<.001)$. 
$\mathrm{N}=311$

Chi Square $=43.187$, d.f. $=36, p=.191$

CFI $=.991$

RMSEA $=.025$

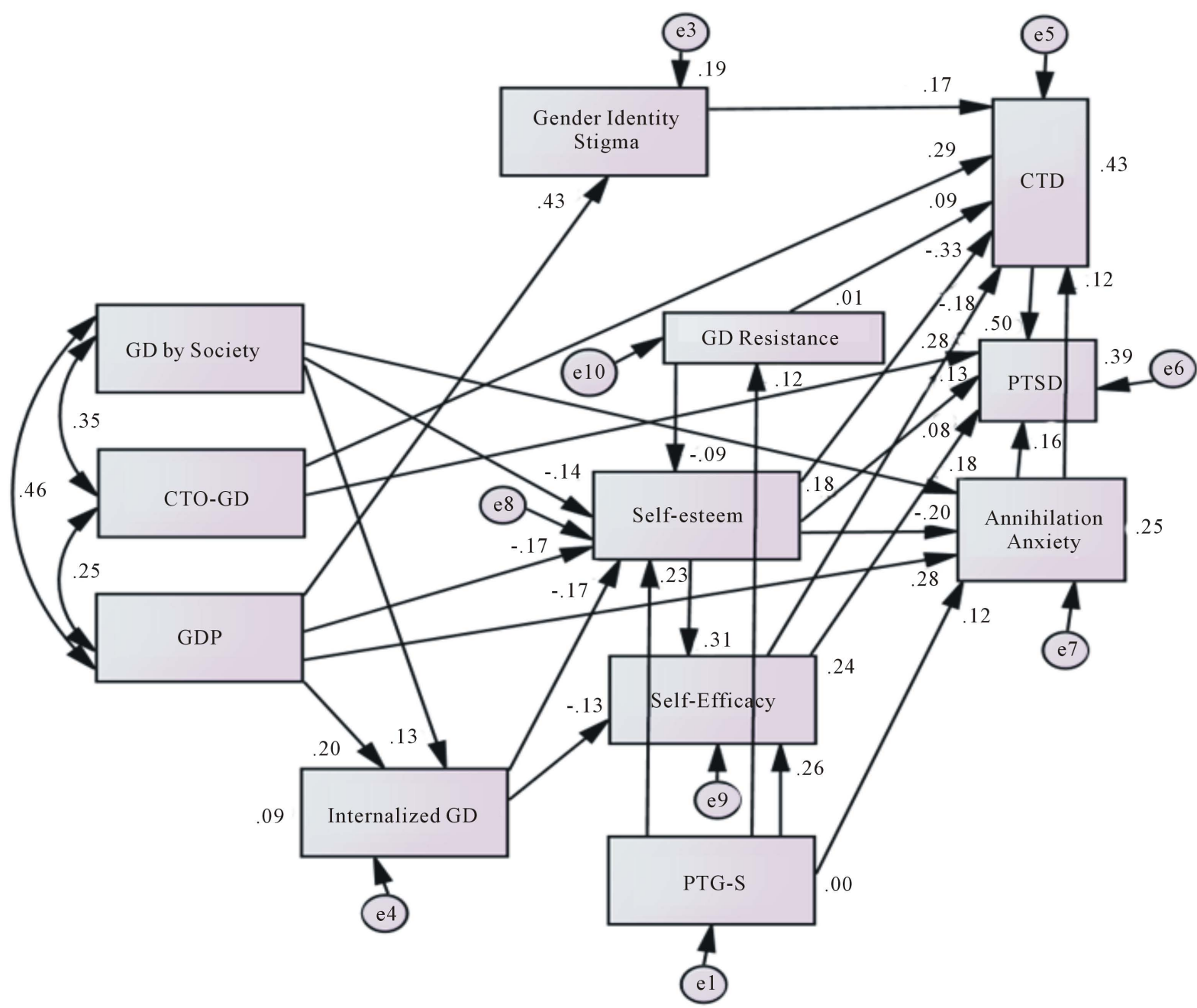

Figure 10. Path diagram for the GD direct Effects on Mental Health variables (cumulative trauma disorders (CTD/complex PTSD, PTSD, existential/annihilation anxieties (AA)) Mediated by Self-esteem and Self-efficacy and Moderated by Gender Identity Conflict (Stigma) (GIC), Gender Discrimination Resistance(GDR), and Internalized Gender Discrimination (IGD), and the contribution of post-traumatic growth to increased self-efficacy, self-esteem and GD resistance.

Table 6. The direct, indirect and total effects and their 95\% confidence intervals of gender discrimination variables on selfesteem, self-efficacy, and on mental health variables.

\begin{tabular}{|c|c|c|c|c|c|c|c|c|}
\hline \multirow{2}{*}{ Causal Variables } & \multicolumn{8}{|c|}{ Endogenous Variables } \\
\hline & GDR & IGD & Self-esteem & AA & GIC & Self-efficacy & CTD & PTSD \\
\hline \multicolumn{9}{|c|}{ GD By Parents } \\
\hline Direct Effects & & $\begin{array}{c}.21^{* *} \\
(.11 / .31)\end{array}$ & $\begin{array}{c}-.17 * * \\
(-.26 /-.08)\end{array}$ & $\begin{array}{c}.28 * * * \\
(.17 / .37)\end{array}$ & $\begin{array}{c}.44 * * * \\
(.34 / .52)\end{array}$ & - & - & $\longrightarrow$ \\
\hline Indirect Effects & & 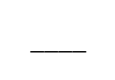 & $\begin{array}{c}-.03 * * \\
(-.06 /-.02)\end{array}$ & $\begin{array}{c}.04 * * \\
(.02 / .07)\end{array}$ & - & $\begin{array}{c}-.09 * * * \\
(-.14 /-.05)\end{array}$ & $\begin{array}{c}.19 * * \\
(.14 / .25)\end{array}$ & $\begin{array}{l}.11^{* *} \\
(.07 / .15)\end{array}$ \\
\hline Total Effects & 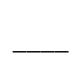 & $\begin{array}{c}.21^{* *} \\
(.11 / .31)\end{array}$ & $\begin{array}{c}-.20 * * \\
(-.30 /-.10)\end{array}$ & $\begin{array}{c}.32 * * * \\
(.21 / .41)\end{array}$ & $\begin{array}{c}.44 * * * \\
(.34 / .52)\end{array}$ & $\begin{array}{c}-.09 * * * \\
(-.14 /-.05)\end{array}$ & $\begin{array}{c}.19 * * \\
(.14 / .25)\end{array}$ & $\begin{array}{c}.11^{* *} \\
(.07 / .15)\end{array}$ \\
\hline
\end{tabular}




\section{Continued}

PTG

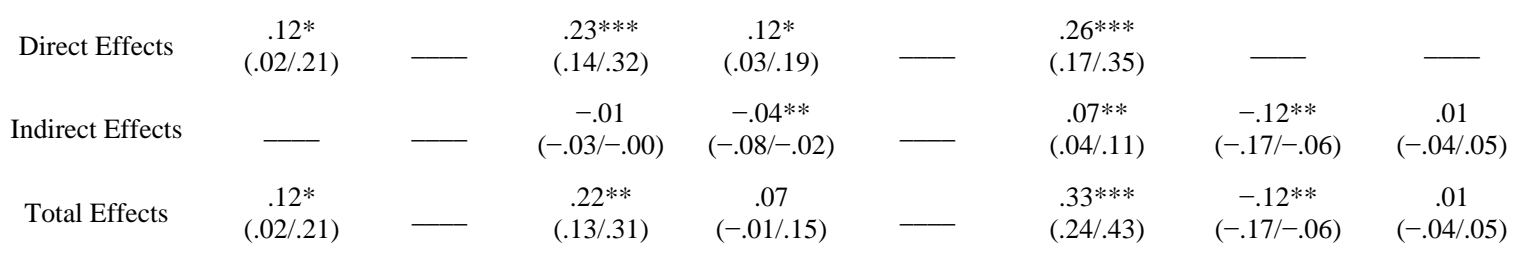

\section{GD By Society}

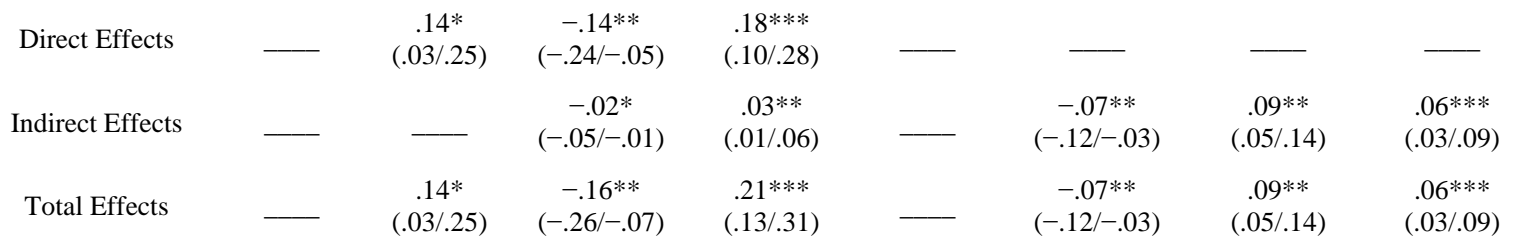

\section{GDR}

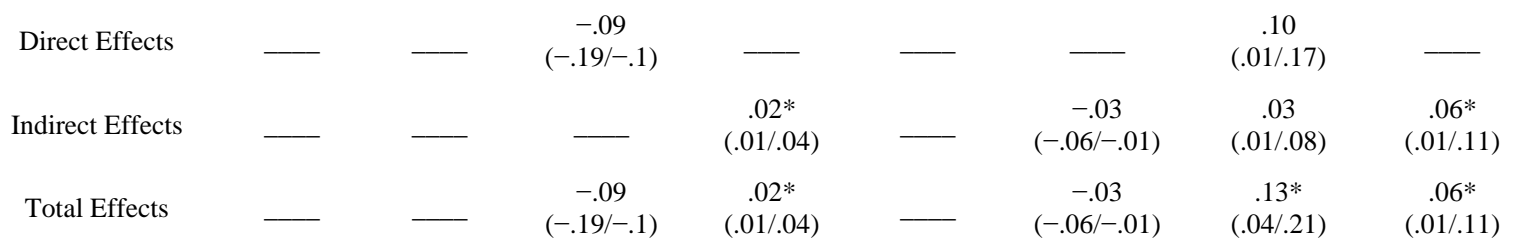

IGD

Direct Effects

$-.17 * *$

Indirect Effects

$(-.25 /-.01)$

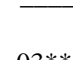

$-.13 *$

$(-.21 /-.04)$

$-.05 * * *$

$(-.09 /-.03)$

Indirect Effects

$.03 * * *$

$(.02 / .04)$

$-.17 * *$

$.03 * * *$

$-.18 * *$

$(.06 / .21) \quad(.01 / .11)$

Total Effects

$(-.25 /-.01)$

$(.02 / .04)$

$.09 * * *$

(.06/.21)

.02

Self-esteem

Direct Effects

$-.20 * * *$

$.31^{* * *}$

(.21/.39)

$-.33 * * *$

$(-.41 /-.26)$

$.13 *$

(-.28/-.10)

$-.08 * * *$

$(.03 / .22)$

Indirect Effects

Total Effects

$-.20 * * *$

-

(-.12/-.05)

$-.21 * * *$

$.31^{* * *}$

$-.41 * *$

(-.29/-.15)

\section{AA}

Direct Effects

(-.28/-.10)

(.21/.39)

(-.49/-.34)

$-.09$

$(-.19 / .01)$

Indirect Effects

Total Effects

GIC

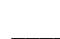

$.12^{* *}$

(.05/.20)

$.16 * * *$
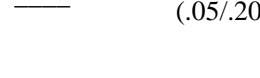

(.08/.23)

$.06 * *$
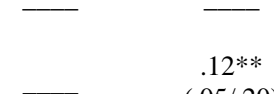

(.02/.11)

$.12 * *$
$(.05 / .20)$

$.22^{* * *}$

(.13/.30)

\section{Direct Effects \\ Indirect Effects \\ Total Effects}




\section{Continued}

Cumulative other Traumas

\begin{tabular}{|c|c|c|c|c|c|c|c|c|}
\hline \multirow[b]{2}{*}{ Direct Effects } & & & & \multirow[b]{2}{*}{-} & \multirow[b]{2}{*}{$\longrightarrow$} & \multirow[b]{2}{*}{ 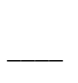 } & \multirow[b]{2}{*}{$\begin{array}{c}.29 * * * \\
(.20 / .38)\end{array}$} & \multirow[b]{2}{*}{$\begin{array}{c}.23 * * * \\
(.13 / .33)\end{array}$} \\
\hline & - & - & $\longrightarrow$ & & & & & \\
\hline Indirect Effects & - & - & - & - & - & - & - & $\begin{array}{c}.15^{* * *} \\
(.10 / .21)\end{array}$ \\
\hline Total Effects & 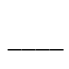 & - & - & - & - & - & $\begin{array}{c}.29 * * * \\
(.20 / .38)\end{array}$ & $\begin{array}{c}.38 * * * \\
(.26 / .49)\end{array}$ \\
\hline \multicolumn{9}{|l|}{ Self-Efficacy } \\
\hline Direct Effects & & & & & & & $\begin{array}{c}-.18 * * \\
(-.27 /-.09)\end{array}$ & $\begin{array}{c}.08 \\
(-.01 / .17)\end{array}$ \\
\hline Indirect Effects & & & & & & & - & $\begin{array}{c}-.09 * * * \\
(-.15 /-.05)\end{array}$ \\
\hline Total Effects & & & & & & & $\begin{array}{c}-.18^{* *} \\
(-.27 /-.09)\end{array}$ & $\begin{array}{c}-.01 \\
(-.10 / .08)\end{array}$ \\
\hline \multicolumn{9}{|l|}{ CTD } \\
\hline Direct Effects & 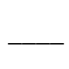 & & & & & & - & $\begin{array}{c}.50 * * * \\
(.40 / .61)\end{array}$ \\
\hline Indirect Effects & - & 工 & 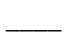 & 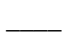 & 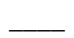 & 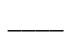 & 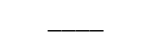 & 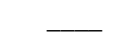 \\
\hline Total Effects & & & & - & - & - & - & $\begin{array}{c}.50 * * * \\
(.40 / .61)\end{array}$ \\
\hline Squared R & .014 & .086 & . 183 & .247 & .189 & .236 & .433 & .393 \\
\hline
\end{tabular}

\section{Discussion: Strengths, Limitations, and Future Directions}

The goal of the two studies was to develop a conceptual model for the dynamics of discrimination that render its negative mental health effects, and test the model using GD as an example as one of these persistent serious stressors that may start at birth and continue over the life span. In two studies, we developed a conceptual model of GD and coping based on DBTF framework, and developed scales to measure their constructs. The final products were six measures that have good construct and predictive validity, as well as accepted alpha and test-retest reliability and can be used in future research. Using the developed measures, we tested the validity of the conceptual model as well as the measures developed. While current research closes some gaps in GD measurement, it confirmed the initial validity and utility of the conceptual model of GD dynamics and the pathways to its negative mental health effects. The outcomes of current research may have implications of the other types of discriminations (other than GD) as well.

The distinction between GD-P and GD-S is one of the contributions of the study. Another important contribution is the findings that highlighted two different trajectories of the effect of GD on mental health. The first trajectory is through its negative effects on self-esteem and self-efficacy that mediate its negative effects on mental health variables. Another trajectory goes through GD direct effects on increasing existential annihilation anxieties (i.e., anxieties related to individual's identity as a female) that mediated GD positive (indirect) effects on increased PTSD and CTD. One of the other important pathways unique to GD-P is its positive effects on gender identity conflict (gender stigma) which mediated its effects on increased CTD. We propose that similar trajectories are operating in other discrimination types. Future studies need to explore such trajectories in other types of discriminations, as well as other potential trajectories specific to each type of discriminations.

The relationships between variables in both studies were significantly linear and gave us the option to test linear path analysis models of their relationships. The results highlighted the serious mental health effects of GD as a continuous chronic potentially traumatic stress, which is rarely addressed in counseling that focus more on past potentially traumatic events. It was long suspected that GD may account for well-known gender differences in psychiatric symptoms (Klonoff, Landrine, \& Campbell, 2000) and their negative mental health effects were 
found to be salient across cultures (Kira et al., 2015). Paradigms that address the mental health consequences of such chronic potentially traumatic events of discrimination that include GD from its roots are emerging (e.g., Kira, Ashby, Omidy, \& Lewandowski, 2015; Kira, Lewandowski, \& Ashby, 2015; Kira, \& Tummala-Narra, 2014), and still need to be further developed.

Future research may focus on comparing the negative effects of gender discrimination on males, as well, as the same dynamics may be in play for males as well. Gender discrimination may Inflate self-esteem (versus deflating it for females), that increases risk taking and externalizing behavior as noticed in comparative research between the two genders.

One of the study limitations is that sample participants are mostly young adults (over $60 \%$ freshman) and most of their experiences of discrimination come from interpersonal interaction, especially within the family. Thus, the resulted measures were mostly focused on their experience in these domains. The GD measures developed here would be optimal for use with adolescents and young adult. To test GD in older adults, we may need to add more items (e.g., from the schedule of sexist events, Klonoff \& Landrine (1995)), that is focused more on GD by social systems and that did not load significantly in the population we studied. Otherwise, the new measures cover new territories in GD measurement rarely measured by the existent GD scales.

Further, the internalized GD scale, while having good construct validity, and high test-retest stability, its internal consistency is rather fair (.60). Adding it to gender identity conflict scale, which may be a twin relative constructs, would increase the internal consistency for the new combined scale adding them together in the current data resulted in the acceptable alpha of .74. Future studies should explore the viability of this option, or work on improving its internal consistency by adding or deleting items.

\section{Conclusion}

To conclude, the study provided a new approach to measuring GD as a continuous traumatic stress experience in family culture by parents and in close relationships, in addition to GD by others and by social systems. Developing precise theoretical models for GD that generate empirically adequate measures and judging competing theoretical accounts by their empirical merits should help in developing our understanding and addressing GD and its negative consequences.

\section{References}

Arber, S., \& Cooper, H. (1999). Gender Differences in Health in Later Life: The New Paradox? Social Science \& Medicine, 48, 61-76. http://dx.doi.org/10.1016/S0277-9536(98)00289-5

Belmi, P., Barragan, R. C., Neale, M. A., \& Cohen, G. L. (2015). Threats to Social Identity Can Trigger Social Deviance . Personality and Social Psychology Bulletin, 41, 467-484. http://dx.doi.org/10.1177/0146167215569493

Betemps, E. J., Smith, R. M., Baker, D. G., \& Rounds-Kugler, B. A. (2003). Measurement Precision of the Clinician Administered PTSD Scale (CAPS): A RASCH Model Analysis. Journal of Applied Measurement, 4, 59-69.

Bharadwaj, P., \& Nelson, B. K. (2012). Discrimination Begins in the Womb-Evidence of Sex Selective Prenatal Investments. Journal of Human Resources, 48, 71-113.

Brescoll, V. L., Uhlmann, E. L., \& Newman, G. E. (2013). The Effects of System-Justifying Motives on Endorsement of Essentialist Explanations for Gender Differences. Journal of Personality and Social Psychology, 105, 891-908. http://dx.doi.org/10.1037/a0034701

Byrne, B. M. (2012). A Primer of LISREL: Basic Applications and Programming for Confirmatory Factor Analytic Models. New York: Springer Science \& Business Media.

Carr, P. B., \& Steele, C. M. (2010). Stereotype Threat Affects Financial Decision Making. Psychological Science, 21, 14111416. http://dx.doi.org/10.1177/0956797610384146

Costello, A. B., \& Osborne, J. W. (2005). Best Practices in Exploratory Factor Analysis: Four Recommendations for Getting the Most from Your Analysis. Practical Assessment, Research \& Evaluation, 10, 2-9. http://pareonline.net

Cattell, R. B. (1966). The Scree Test for the Number of Factors. Multivariate Behavioral Research, 1, 245-276.

Corrigan, P. W., Watson, A. C., \& Barr, L. (2006). The Self-Stigma of Mental Illness: Implications for Self-Esteem and SelfEfficacy. Journal of Social \& Clinical Psychology, 25, 875-884. http://dx.doi.org/10.1521/jscp.2006.25.8.875

Crosby, F. (1984). The Denial of Personal Discrimination. American Behavioral Psychologist, 27, 371-386. http://dx.doi.org/10.1177/000276484027003008

DeHart, T., Peña, R., \& Tennen, H. (2013). The Development of Explicit and Implicit Self-Esteem and Their Role in Psy- 
chological Adjustment. In V. Zeigler-Hill, Ed., Self-Esteem: Current Issues in Social Psychology (pp. 99-123). New York: Psychology Press.

Denton, M., \& Walters, V. (1999). Gender Differences in Structural and Behavioural Determinants of Health: An Analysis of the Social Production of Health. Social Science \& Medicine, 48, 1221-1235. http://dx.doi.org/10.1016/S0277-9536(98)00421-3

Elhai, J. D., Lindsay, B. M., Gray, M. J., Grubaugh, A. L., North, T. C., \& Frueh, B. C. (2006). Examining the Uniqueness of Frequency and Intensity Symptom Ratings in Posttraumatic Stress Disorder Assessment. Journal of Nervous and Mental Disease, 194, 940-944. http://dx.doi.org/10.1097/01.nmd.0000243011.76105.4b

Freyd, J. J., Klest, B., \& Allard, C. B. (2005). Betrayal Trauma: Relationship to Physical Health, Psychological Distress, and a Written Disclosure Intervention. Journal of Trauma \& Dissociation, 6, 83-104. http://dx.doi.org/10.1300/J229v06n03_04

Garcia, D. M., Schmitt, M., Branscombe, N., \& Ellemers, N. (2010). Women’s Reactions to In-Group Members Who Protest Discriminatory Treatment: The Importance of Beliefs about Inequality and Response Appropriateness. European Journal of Social Psychology, 40, 733-745.

Gibbons, F. X., O’Hara, R. E., Stock, M. L., Gerrard, M., Weng, C. Y., \& Wills, T. A. (2012). The Erosive Effects of Racism: Reduced Self-Control Mediates the Relation between Perceived Racial Discrimination and Substance Use in Black American Adolescents. Journal of Personality and Social Psychology, 102, 1089-1104. http://dx.doi.org/10.1037/a0027404

Gino, F., Schweitzer, M. E., Mead, N. L., \& Ariely, D. (2011). Unable to Resist Temptation: How Self-Control Depletion Promotes Unethical Behavior. Organizational Behavior and Human Decision Processes, 115, 191-203. http://dx.doi.org/10.1016/j.obhdp.2011.03.001

Glick, P., \& Fiske, S. T. (1996). The Ambivalent Sexism Inventory: Differentiating Hostile and Benevolent Sexism. Journal of Personality and Social Psychology, 70, 491-512. http://dx.doi.org/10.1037/0022-3514.70.3.491

Helms, J., Nicolas, G., \& Green, C. (2012). Racism and Ethno-Violence as Trauma: Enhancing Professional and Research Training. Traumatology, 18, 65-74. http://dx.doi.org/10.1177/1534765610396728

Henson, R. K., \& Roberts, J. K. (2006). Use of Exploratory Analysis in Published Research: Common Errors and Some Comments on Improved Practice. Educational and Psychological Measurement, 66, 393-416. http://dx.doi.org/10.1177/0013164405282485

Inzlicht, M., \& Kang, S. K. (2010). Stereotype Threat Spillover: How Coping with Threats to Social Identity Affects Aggression, Eating, Decision Making, and Attention. Journal of Personality and Social Psychology, 99, 467-481. http://dx.doi.org/10.1037/a0018951

Johnson, R. E., Rosen, C. C., \& Levy, P. E. (2008). Getting to the Core of Core Self-Evaluations: A Review and Recommendations. Journal of Organizational Behavior, 29, 391-413. http://dx.doi.org/10.1002/job.514

Jost, J. T., Banaji, M. R., \& Nosek, B. A. (2004). A Decade of System Justification Theory: Accumulated Evidence of Conscious and Unconscious Bolstering of the Status Quo. Political Psychology, 25, 881-919. http://dx.doi.org/10.1111/j.1467-9221.2004.00402.x

Judge, T. A., \& Bono, J. E. (2001). A Rose by Any Other Name: Are Self-Esteem, Generalized Self-Efficacy, Neuroticism, and Locus of Control Indicators of a Common Construct. In B. W. Roberts, \& R. Hogan (Eds.), Personality Psychology in the Workplace: Decade of Behavior (pp. 93-118). Washington DC: American Psychological Association. http://dx.doi.org/10.1037/10434-004

Kamans, E., Gordijn, E. H., Oldenhuis, H., \& Otten, S. (2009). What I Think You See Is What You Get: Influence of Prejudice on Assimilation to Negative Meta-Stereotypes among Dutch Moroccan Teenagers. European Journal of Social Psychology, 39, 842-851. http://dx.doi.org/10.1002/ejsp.593

Kaufman, J. M. (2009). Gendered Responses to Serious Strain: The Argument for a General Strain Theory of Deviance. Justice Quarterly, 26, 410-444. http://dx.doi.org/10.1080/07418820802427866

Kira, I., Abou-Medien, S., Ashby, J., Lewandowski, L., Meohanesh, J., \& Odenat, L. (2012). Post-Traumatic Growth Inventory: Psychometric Properties of the Arabic Version in Palestinian Adults. The International Journal of Educational and Psychological Assessment, 11, 120-137.

Kira, I., Abou-Mediene, S., Ashby, J., Odenat, L., Mohanesh, J., \& Alamia, H. (2013). The Dynamics of Post-Traumatic Growth across Different Trauma Types in a Palestinian Sample. Journal of Loss and Trauma: International Perspectives on Stress \& Coping, 18, 120-139. http://dx.doi.org/10.1080/15325024.2012.679129

Kira, I., Alawneh, A., Aboumediene, S., Lewandowski, L., \& Laddis, A. (2014). Dynamics of Oppression and Coping from Traumatology Perspective: The Example of Palestinian Youth. Peace and Conflict: Journal of Peace Psychology, 20, 385411. http://dx.doi.org/10.1037/pac0000053

Kira, I., Ashby, J. S., Lewandowski, L., Alawneh, A. N., Mohanesh, J., \& Odenat, L. (2013). Advances in Continuous Traumatic Stress Theory: Traumatogenic Dynamics and Consequences of Intergroup Conflict: The Palestinian Adoles- 
cents’ Case. Psychology, 4, 396-409. http://dx.doi.org/10.4236/psych.2013.44057

Kira, I., Ashby, J., Lewandowski, L., Smith, I., \& Odenat, L. (2012). Gender Inequality and Its Effects in Females Torture Survivors. Psychology, 3, 352-363. http://dx.doi.org/10.4236/psych.2012.34050

Kira, I., Ashby, J. S., Omidy, A. Z., \& Lewandowski, L. (2015). Current, Continuous, and Cumulative Trauma-Focused Cognitive Behavior Therapy (CCC-TF-CBT). Journal of Mental Health Counseling, 37, 323-340. http://dx.doi.org/10.17744/mehc.37.4.04

Kira, I., Fawzi, M., \& Fawzi, M. (2013). The Dynamics of Cumulative Trauma and Trauma Types in Adults Patients with Psychiatric Disorders: Two Cross-Cultural Studies. Traumatology: An International Journal, 19, 179-195. http://dx.doi.org/10.1177/1534765612459892

Kira, I., Lewandowski, L., \& Ashby, J. S. (2015). Development and Piloting the MMMM Ecological Interactive Open Systems Model: A Prospective One-Year Treatment Outcomes of Children of Tortured Refugees. Psychology, 6, 1277-1296. http://dx.doi.org/10.4236/psych.2015.610125

Kira, I. A., Lewandowski, L., Ashby, J. S., Templin, T., Ramaswamy, V., \& Mohanesh, J. (2014). The Traumatogenic Dynamics of Internalized Stigma of Mental Illness among Arab Americans, Muslims, and Refugees Clients. Journal of the American Psychiatric Nurses Association, 20, 250-266. http://dx.doi.org/10.1177/1078390314542873

Kira, I., Lewandowski, L., Chiodo, L., \& Ibrahim, A. (2014). Advances in Systemic Trauma Theory: Traumatogenic Dynamics and Consequences of Backlash as a Multi-Systemic Trauma on Iraqi Refugee Muslim Adolescents. Psychology, 5 , 389-412. http://dx.doi.org/10.4236/psych.2014.55050

Kira, I., Lewandowski, L., Templin, T., Ramaswamy, V., Ozkan, B., \& Mohanesh, J. (2008). Measuring Trauma Dose, Types and Profiles Using a Development-Based Taxonomy of Trauma. Traumatology: International Journal, $14,62-87$.

Kira, I. A., Omidy, A. Z., \& Ashby, J. S. (2014). Cumulative Trauma, Appraisal, and Coping in Palestinian and American Indian Adults: Two Cross-Cultural Studies. Traumatology: An International Journal, 20, 119-133. http://dx.doi.org/10.1037/h0099397

Kira, I. A., Omidy, A. Z., Fawzi, M., Rice, K. G., Fawzi, M., Lewandowski, L., \& Bujold-Bugeaud, M. (2015). Are the Negative Mental Health Effects of Gender Discrimination (GD) Salient across Cultures? Does Self-Esteem Mediate These Effects: GD as a Continuous Traumatic Stress and the Pathways to Its Negative Dynamics? Psychology, 6, 93-116. http://dx.doi.org/10.4236/psych.2015.61009

Kira, I., Smith, I., Lewandowski, L., \& Templin, T. (2010).The Effects of Perceived Gender Discrimination on Refugee Torture Survivors: A Cross-Cultural Traumatology Perspective. Journal of the American Psychiatric Nurses Association, 16, 299-306. http://dx.doi.org/10.1177/1078390310384401

Kira, I., Templin, T., Lewandowski, L., Ashby, J. S., Oladele, A., \& Odenat, L. (2012). Cumulative Trauma Disorder Scale: Two Studies. Psychology, 3, 643-656. http://dx.doi.org/10.4236/psych.2012.39099

Kira, I., Templin, T., Lewandowski, L., Clifford, D., Wiencek, E., Hammad, A., Al-Haidar, A., \& Mohanesh, J. (2006). The Effects of Torture: Two Community Studies. Peace and Conflict: Journal of Peace Psychology, 12, 205-228. http://dx.doi.org/10.1207/s15327949pac1203_1

Kira, I., Templin, T., Lewandowski, L., Ramaswamy, V., Bulent, O., Mohanesh, J., \& Abdulkhaleq, H. (2012). Collective and Personal Annihilation Anxiety: Measuring Annihilation Anxiety AA. Psychology, 3, 90-99. http://dx.doi.org/10.4236/psych.2012.31015

Kira, I., \& Tummala-Narra, P. (2014). Psychotherapy with Refugees: Emerging Paradigm. Journal of Loss and Trauma: International Perspectives on Stress \& Coping, Online First Publication.

Kling, K. C., Hyde, J. S., Showers, C. J., \& Buswell, B. N. (1999). Gender Differences in Self-Esteem: A Meta-Analysis. Psychological Bulletin, 125, 470-500. http://dx.doi.org/10.1037/0033-2909.125.4.470

Klonoff, E. A., Landrine, H., \& Campbell, R. (2000). Sexist Discrimination May Account for Well-Known Gender Differences in Psychiatric Symptoms. Psychology of Women Quarterly, 24, 93-99. http://dx.doi.org/10.1111/j.1471-6402.2000.tb01025.x

Klonoff, E. A., \& Landrine, H. (1995). The Schedule of Sexist Events: A Measure of Lifetime and Recent Sexist Discrimination in Women's Lives. Psychology of Women Quarterly, 19, 439-472. http://dx.doi.org/10.1111/j.1471-6402.1995.tb00086.x

Luszczynska, A., Scholz, U., \& Schwarzer, R. (2005). The General Self-Efficacy Scale: Multicultural Validation Studies. Journal of Psychology: Interdisciplinary and Applied, 139, 439-457. http://dx.doi.org/10.3200/JRLP.139.5.439-457

Major, B., Barr, L., Zubek, J., \& Babey, S. H. (1999). Gender and Self-Esteem: A Meta-Analysis. In W. B. Swann, J. H. Langlois, \& L. A. Gilbert (Eds.), Sexism and Stereotypes in Modern Society: The Gender Science of Janet Taylor Spence (pp. 223-253). Washington DC: American Psychological Association. http://dx.doi.org/10.1037/10277-009

Mann, M., Hosman, C. M., Schaalma, H. P., \& de Vries, N. K. (2004). Self-Esteem in a Broad-Spectrum Approach for 
Mental Health Promotion. Health Education Research, 19, 357-372. http://dx.doi.org/10.1093/her/cyg041

McMullin, J. A., \& Cairney, J. (2004). Self-Esteem and the Intersection of Age, Class, and Gender. Journal of Aging Studies, 18, 75-90. http://dx.doi.org/10.1016/j.jaging.2003.09.006

Millender, E. I. (2013). Cumulative Trauma among Adult Mayas Living in Southeast Florida. PhD Dissertation, Boca Raton, FL: Florida Atlantic University, 196 p.

O’connor, B. P. (2000). SPSS and SAS Programs for Determining the Number of Components Using Parallel Analysis and Velicer's MAP Test. Behavior Research Methods, Instruments, \& Computers, 32, 396-402. http://dx.doi.org/10.3758/BF03200807

Orth, U., Robins, R. W., \& Widaman, K. F. (2012). Life-Span Development of Self-Esteem and Its Effects on Important Life Outcomes. Journal of Personality and Social Psychology, 102, 1271-1288. http://dx.doi.org/10.1037/a0025558

Orth, U., Robins, R. W., Widaman, K. F., \& Conger, R. D. (2013). Is Low Self-Esteem a Risk Factor for Depression? Findings from a Longitudinal Study of Mexican-Origin Youth. Developmental Psychology, 50, 622-633. http://dx.doi.org/10.1037/a0033817

Pascoe, E. A., \& Richman, S. L. (2009). Perceived Discrimination and Health: A Meta-Analytic Review. Psychological Bulletin, 135, 531-554. http://dx.doi.org/10.1037/a0016059

Quinn, D., Kallen, R., Twenge, J., \& Fredrickson, B. (2006). The Disruptive Effect of Self-Objectification on Performance. Psychology of Women Quarterly, 30, 59-64. http://dx.doi.org/10.1111/j.1471-6402.2006.00262.x

Rosenberg, M. (1965). Society and the Adolescent Self-Image. Princeton, NJ: Princeton University Press.

Rosenfield, S., Lennon, M. C., \& White, H. R. (2005). The Self and Mental Health: Self-Salience and the Emergence of Internalizing and Externalizing Problems. Journal of Health and Social Behavior, 46, 323-340. http://dx.doi.org/10.1177/002214650504600402

Schmitt, M. T., Branscombe, N. R., Postmes, T., \& Garcia, A. (2014). The Consequences of Perceived Discrimination for Psychological Well-Being: A Meta-Analytic Review. Psychological Bulletin, 140, 921-948. http://dx.doi.org/10.1037/a0035754

Scholz, U., Dona, B. G., Sud, S., \& Schwarzer, R. (2002). Is General Self-Efficacy a Universal Construct? Psychometric Findings from 25 Countries. European Journal of Psychological Assessment, 18, 242-251. http://dx.doi.org/10.1027//1015-5759.18.3.242

Schwarzer, R., \& Jerusalem, M. (1995). Generalized Self-Efficacy Scale. In: J. Weinman, S. Wright, \& M. Johnson (Eds.), Measures in Health Psychology: A User's Portfolio, Causal and Control Beliefs (pp. 35-37). Windsor: NFER-NELSON.

Sidanius, J., \& Pratto, F. (1999). Social Dominance: An Intergroup Theory of Social Hierarchy and Oppression. New York: Cambridge University Press. http://dx.doi.org/10.1017/CBO9781139175043

Steele, C. M., \& Aronson, J. (1995). Stereotype Threat and the Intellectual Test Performance of Black Americans. Journal of Personality and Social Psychology, 69, 797-811. http://dx.doi.org/10.1037/0022-3514.69.5.797

Sowislo, J. F., \& Orth, U. (2013). Does Low Self-Esteem Predict Depression and Anxiety? A Meta-Analysis of Longitudinal Studies. Psychological Bulletin, 139, 213-240. http://dx.doi.org/10.1037/a0028931

Steinberg, J. A., Karpinski, A., \& Alloy, L. B. (2007). The Exploration of Implicit Aspect of Self-Esteem in VulnerabilityStress Models of Depression. Self-Identity, 6, 101-117. http://dx.doi.org/10.1080/15298860601118884

Swim, J., Aikin, K., Hall, W., \& Hunter, A. (1995). Sexism and Racism: Old-Fashioned and Modern Prejudices. Journal of Personality and Social Psychology, 68, 199-214. http://dx.doi.org/10.1037/0022-3514.68.2.199

Tedeschi, R. G., \& Calhoun, L. G. (1996). The Posttraumatic Growth Inventory: Measuring the Positive Legacy of Trauma. Journal of Traumatic Stress, 9, 455-471. http://dx.doi.org/10.1002/jts.2490090305

Trzesniewski, K. H., Donnellan, M. B., Moffitt, T. E., Robins, R. W., Poulton, R., \& Caspi, A. (2006). Low Self-Esteem during Adolescence Predicts Poor Health, Criminal Behavior, and Limited Economic Prospects during Adult-Hood. Developmental Psychology, 42, 381-390. http://dx.doi.org/10.1037/0012-1649.42.2.381

Yeung, A. W. Y., Kay, A. C., \& Peach, J. M. (2014). Anti-Feminist Backlash: The Role of System Justification in the Rejection of Feminism. Group Processes and Intergroup Relations, 17, 474-484. http://dx.doi.org/10.1177/1368430213514121

Yoon, E., Adams, K., Hogge, I., Bruner, J. P., Surya, S., \& Bryant, F. B. (2015). Development and Validation of the Patriarchal Beliefs Scale. Journal of Counseling Psychology, Advance Online Publication. http://dx.doi.org/10.1037/cou0000056

van de Vijver, F. J. R., \& Hambleton, R. K. (1996). Translating Tests: Some Practical Guidelines. European Psychologist, 1, 89-99. http://dx.doi.org/10.1027/1016-9040.1.2.89

Wanous, J., \& Hudy, M. J. (2001). Single-Item Reliability: A Replication and Extension. Organizational Research Methods, 4, 361-375. http://dx.doi.org/10.1177/109442810144003 
Weathers, F., Keane, T., \& Davidson, J. (2001). The Clinician-Administered PTSD Scale: A Review of the First Ten Years of Research. Depression and Anxiety, 13, 132-156. http://dx.doi.org/10.1002/da.1029

Weston, R., \& Gore, P. (2006). A Brief Guide to Structural Equation Modeling. The Counseling Psychologist, 34, 719-751. http://dx.doi.org/10.1177/0011000006286345 


\section{Appendix 1}

\section{Gender Discrimination Inventory for Female Adolescents and Adults (33 items)}

A. Gender Discrimination Scales (21 items)

1. Gender Discrimination by Parents’ attitudes Scale (7 items).

2. Gender Discrimination by Parents' Behavior Scale (6 items).

3. Gender Discrimination by Society Scale. (8 items) (adapted from Schedule of Sexist Events Scale)

B. Gender Discrimination coping scales (12 items)

1. Internalized Gender Discrimination Scale (IGD) Sub-scale (4 items).

2. Gender Identity Conflict (Gender Stigma) Scale (GIC) Sub-scale (4 items).

3. Gender Discrimination Resistance (GDR) Sub-scale (4 items).

\section{Gender Discrimination Scales}

\section{Gender Discrimination by Parents' Attitudes Scale (GD-Pa)}

For each of these following statements (in this scale and for all the following scales), please circle the number that best that indicates how much you agree or disagree with the statement according to the following scale:

1. I strongly disagree.

2. Disagree

3. I am not sure/or do not apply.

4. I agree.

5. I strongly agree.

1. One of my parents has/had negative attitudes toward me due to my gender.

$$
\begin{array}{lllll}
1 & 2 & 3 & 4 & 5
\end{array}
$$

2. I have been told by some family members that girls have less worth than boys.

$$
\begin{array}{lllll}
1 & 2 & 3 & 4 & 5
\end{array}
$$

3. One of my parents (or both parents) neglected me because I am a girl.

$$
\begin{array}{lllll}
1 & 2 & 3 & 4 & 5
\end{array}
$$

4. My family generally prefers boys.

$$
\begin{array}{lllll}
1 & 2 & 3 & 4 & 5
\end{array}
$$

5. My father prefers to have boys.

$$
\begin{array}{lllll}
1 & 2 & 3 & 4 & 5
\end{array}
$$

6. My mother prefers to have boys.

$$
\begin{array}{lllll}
1 & 2 & 3 & 4 & 5
\end{array}
$$

7. $\quad$ One of my parents discriminated against me because of my gender.

$$
\begin{array}{lllll}
1 & 2 & 3 & 4 & 5
\end{array}
$$

\section{Gender Discrimination by Parents' Behavior Scale (GD-Pb)}

8. My parents trust more and give greater liberty to boys than girls in choosing their friends.

$$
\begin{array}{lllll}
1 & 2 & 3 & 4 & 5
\end{array}
$$

9. My parents trust more and give greater liberty to boys than girls in choosing their future spouse

$$
\begin{array}{lllll}
1 & 2 & 3 & 4 & 5
\end{array}
$$

10. My parents trust more and give greater liberty to boys than girls in choosing their education and career paths. 


\section{$\begin{array}{lllll}1 & 2 & 3 & 4 & 5\end{array}$}

11. My Parents give/gave more freedom to my brother/s in choosing what cloth to buy because I am a girl.

$$
\begin{array}{lllll}
1 & 2 & 3 & 4 & 5
\end{array}
$$

12. My parents put limitations and more control on my using the internet and/ or the mobile phone, that does not put on my brother/s.

$$
\begin{array}{lllll}
1 & 2 & 3 & 4 & 5
\end{array}
$$

13. My parent set stricter curfew time on me compared to my brother/s.

$$
\begin{array}{lllll}
1 & 2 & 3 & 4 & 5
\end{array}
$$

\section{Gender Discrimination by Society Scale (GD-S)}

Please think carefully about your life as you answer the questions below. For each question, read the question and then answer for what your ENTIRE LIFE (from when you were a child to now) has been like. Circle the number that best describes events in YOUR ENTIRE LIFE using these rules:

Circle $1=$ If the event has NEVER happened to you

Circle 2 = If the event happened ONCE IN A WHILE (less than $10 \%$ of the time)

Circle $3=$ If the event happened SOMETIMES (10\% - 25\% of the time)

Circle 4 = If the event happened A LOT (26\% - 49\% of the time)

Circle $5=$ If the event happened MOST OF THE TIME (50\% - 70\% of the time)

Circle 6 = If the event happened ALMOST ALL OF THE TIME (more than $70 \%$ of the time)

1. How many times have you been treated unfairly by strangers because you are a woman?

$$
\begin{array}{llllll}
1 & 2 & 3 & 4 & 5 & 6
\end{array}
$$

2. How many times have you been treated unfairly by neighbors because you are a woman?

$$
\begin{array}{llllll}
1 & 2 & 3 & 4 & 5 & 6
\end{array}
$$

3. How many times have people failed to show you the respect that you deserve because you are a girl/a woman?

$$
\begin{array}{llllll}
1 & 2 & 3 & 4 & 5 & 6
\end{array}
$$

4. How many times have you wanted to tell someone off for being sexist?

$$
\begin{array}{llllll}
1 & 2 & 3 & 4 & 5 & 6
\end{array}
$$

5. How many times have you been really angry about something sexist that was done to you?

$$
\begin{array}{llllll}
1 & 2 & 3 & 4 & 5 & 6
\end{array}
$$

6. How many times have you been called a sexist name like a bitch, cunt, chick, or other names?

$$
\begin{array}{llllll}
1 & 2 & 3 & 4 & 5 & 6
\end{array}
$$

7. How many times have you been made fun of, picked on, pushed, shoved, hit, or threatened with harm because you are a woman/a girl?

$$
\begin{array}{llllll}
1 & 2 & 3 & 4 & 5 & 6
\end{array}
$$

8. How many times have you heard people making sexist jokes or degrading sexual jokes?

$$
\begin{array}{llllll}
1 & 2 & 3 & 4 & 5 & 6
\end{array}
$$

\section{Gender Discrimination Coping Scales}

For each of these following statements (in this scale and for all the following scales), please circle the number that best that indicates how much you agree or disagree with the statement according to the following scale:

1. I strongly disagree. 


\section{Disagree}

3. I am not sure/or do not apply.

4. I agree.

5. I strongly agree.

\section{Internalized Gender Discrimination Subscale A (IGD)}

1) I am happy being a girl/woman depending on a man.

\section{$\begin{array}{lllll}1 & 2 & 3 & 4 & 5\end{array}$}

2) One of the characteristics of females is the dependency because God created her weak.

$$
\begin{array}{lllll}
1 & 2 & 3 & 4 & 5
\end{array}
$$

3) I tend to be manageable/easy (surrender) because I am a female.

$$
\begin{array}{lllll}
1 & 2 & 3 & 4 & 5
\end{array}
$$

4) Because I am a girl, I need others to make some decisions for me.

$$
\begin{array}{lllll}
1 & 2 & 3 & 4 & 5
\end{array}
$$

\section{Internalized Gender Discrimination Subscale B (Gender Identity conflict GIC)}

1) I would rather be a boy if I could', I wish I were a boy.

$$
\begin{array}{lllll}
1 & 2 & 3 & 4 & 5
\end{array}
$$

2) I am disappointed in myself because I am a female.

$\begin{array}{lllll}1 & 2 & 3 & 4 & 5\end{array}$

3) If I have a choice, I would rather not to be born at all as a girl.

$$
\begin{array}{lllll}
1 & 2 & 3 & 4 & 5
\end{array}
$$

4) Being a girl (not a boy or a man) has spoiled my life.

$$
\begin{array}{lllll}
1 & 2 & 3 & 4 & 5
\end{array}
$$

\section{Gender Discrimination Resistance Scale (GDR)}

1) I am a feminist who fights against gender discrimination and the injustice.

$$
\begin{array}{lllll}
1 & 2 & 3 & 4 & 5
\end{array}
$$

2) Subtle and blatant acts of discrimination because of being female and against my gender make me angry.

$$
\begin{array}{lllll}
1 & 2 & 3 & 4 & 5
\end{array}
$$

3) I fight against discriminations and the injustice.

$$
\begin{array}{lllll}
1 & 2 & 3 & 4 & 5
\end{array}
$$

4) I am against the transgenerational transmission of old age and ongoing gender discrimination

$$
\begin{array}{lllll}
1 & 2 & 3 & 4 & 5
\end{array}
$$

\section{Short Form for GDR Scale (GDR-S)}

1. I am a feminist who fight against gender discrimination and the injustice.

$$
\begin{array}{lllll}
1 & 2 & 3 & 4 & 5
\end{array}
$$

2. I fight against discriminations and the injustice.

$$
\begin{array}{lllll}
1 & 2 & 3 & 4 & 5
\end{array}
$$


Items recommended to being added to GD-S for older non-house wives adults (items from Schedule of $\underline{\text { Sexist Events Scale) }}$

1) How many times were you denied a raise, a promotion, tenure, a good assignment, a job, or other such things at work that you deserved because you are a girl/woman?

2) How many times have you been treated unfairly by your employer, boss or supervisors because you are a woman?

3) How many times were you forced to take drastic steps (such as filing a grievance, filing a lawsuit, quitting your job, moving away, and other actions) to deal with some sexist thing that was done to you? 